\title{
Selected Topics from Recent NMR Studies of Organolithium
}

\section{Compounds}

\section{Harald Günther}

\author{
University of Siegen, FB 8, OCII \\ D-57068 Siegen, Germany
}

\begin{abstract}
Após uma breve introdução à espectroscopia de RMN de metais alcalinos e alcalino terrosos, esta revisão concentra-se nas investigações de RMN em compostos organo-lítios. O método de impressão digital isotópica, que baseia-se no deslocamento das ressonâncicas de ${ }^{6} \mathrm{Li}$ induzido por deutério, é apresentado e exemplificado com aplicações sobre o comportamento de agregação de sistemas de ciclopropil-lítio e formação de agregados mistos entre metil-lítio e sais de lítio. No capítulo seguinte discutem-se experimentos uni- e bidimensionais, tanto para sistemas de spin homonucleares quanto heteronucleares. Finalmente, descrevem-se os aspectos estruturais associados ao benzil-lítio e a formação de sistemas poli-lítio pela redução de bifenilas por lítio.
\end{abstract}

After a short introduction to NMR spectroscopy of alkali and alkaline earth metals the review concentrates on NMR investigations of organolithium compounds. The isotopic fingerprint method, which rests on deuterium-induced isotope shifts for ${ }^{6} \mathrm{Li}$ resonances, is introduced and exemplified with applications from the aggregation behavior of cyclopropyllithium systems and mixed aggregate formation between methyllithium and lithium salts. In the following chapter, one- and two-dimensional pulse experiments, both for homo- and for heteronuclear spin systems are discussed. Finally, the structural aspects associated with benzyllithium are outlined and the formation of polylithium systems by lithium reduction of biphenylenes is described.

Keywords: $N M R,{ }^{6}$ Li-NMR, ${ }^{15} N$-NMR, isotope shifts, isotopic fingerprints, pulse methods, spin-spin coupling, organolithium compounds, aggregation, benzyllithium structure, $\pi$-systems, polylithium systems, reduction

\section{Introduction}

The alkaline and alkaline earth metals, a group of elements which comprises the four biologically most important cations $\left(\mathrm{Na}^{+}, \mathrm{K}^{+}, \mathrm{Ca}^{2+}, \mathrm{Mg}^{2+}\right)$, provides us with an appreciable number of magnetic nuclei (Table $1^{1,2}$ ). No wonder then, that NMR spectroscopy finds widespread applications, including such diverse topics like ion solvation in solution, investigations of ion binding to biological macromolecules and enzymes, solid state NMR of minerals and metal-doped fullerenes, as well as sodium NMR imaging.

With respect to investigations of structure and dynamics in organometallic chemistry, however, high-resolution NMR spectroscopy of most of these nuclides suffers from large quadrupole moments which lead to severe line broadening. Notable exceptions are beryllium, ${ }^{9} \mathrm{Be}$, cesium, ${ }^{133} \mathrm{Cs}$, and in particular the lithium isotopes ${ }^{6} \mathrm{Li}$ and ${ }^{7} \mathrm{Li}$ which can be successfully employed in various one- and two-dimensional NMR experiments. Especially ${ }^{6} \mathrm{Li}$, which has the smallest quadrupole moment of all stable nuclides and which has been classified ludicrously as an 'honorary spin-1/2 nucleus ${ }^{3}$, is an important tool for the elucidation of structure and dynamics in lithiated carbon, nitrogen, and phosphorus compounds.

A concise and informative review on NMR of alkali and alkaline earth metals was lately given by $\mathrm{Akitt}^{2}$, who also lists the earlier progress reports for this field. Laszlo ${ }^{3,4}$ and Lutz $^{5}$ provided additional articles, as did Drakenberg ${ }^{6}$ and just recently again Laszlo ${ }^{7}$. Several extensive progress reports dealing with ${ }^{6,7} \mathrm{Li}-\mathrm{NMR}$ have appeared ${ }^{8-13}$, a fact which underlines the continuous activity in this area. On the other hand, the biological importance of certain group I and II metals like sodium, magnesium, and calcium has initiated numerous NMR investigations of the respective nuclides in biological systems and results from this field, including accounts on sodium NMR imaging, have been summarized by several authors ${ }^{14-22}$. In addition, completely 
Table 1. Nuclear properties of stable alkali and alkaline earth metal isotopes ${ }^{\mathrm{a}}$.

\begin{tabular}{|c|c|c|c|c|c|c|}
\hline Isotope & $\begin{array}{c}\text { Natural } \\
\text { abundance }(\%)\end{array}$ & $\begin{array}{c}\text { Spin quantum } \\
\text { number I }\end{array}$ & $\begin{array}{c}\mathrm{v}_{1} \text { at } 9.4 \mathrm{~T} \\
\left({ }^{1} \mathrm{H}=400 \mathrm{MHz}\right)\end{array}$ & $\begin{array}{l}\text { Quadrupole moment } \\
\text { Q }\left(10^{-28} \mathrm{~m}^{2}\right)\end{array}$ & $\begin{array}{c}\text { Receptivity } D^{1} \\
\left({ }^{13} \mathrm{C}=1.00\right)\end{array}$ & $\begin{array}{c}\text { Width factor } \\
\left({ }^{7} \mathrm{Li}=1.0\right)\end{array}$ \\
\hline${ }^{6} \mathrm{Li}$ & 7.42 & 1 & 58.862 & $-8 \times 10^{-4}$ & 3.58 & $2.0 \times 10^{-3}$ \\
\hline${ }^{7} \mathrm{Li}$ & 92.58 & $3 / 2$ & 155.454 & $-4.5 \times 10^{-2}$ & 1540 & 1.00 \\
\hline${ }^{23} \mathrm{Na}$ & 100.0 & $3 / 2$ & 105.805 & 0.12 & 525 & 343 \\
\hline${ }^{39} \mathrm{~K}$ & 93.1 & $3 / 2$ & 18.666 & $5.5 \times 10^{-2}$ & 2.69 & 1359 \\
\hline${ }^{41} \mathrm{~K}$ & 6.88 & $3 / 2$ & 10.245 & $6.7 \times 10^{-2}$ & 0.0328 & - \\
\hline${ }^{85} \mathrm{Rb}$ & 72.15 & $5 / 2$ & 38.620 & 0.25 & 43 & 54200 \\
\hline${ }^{87} \mathrm{Rb}$ & 27.85 & $3 / 2$ & 130.885 & 0.12 & 277 & - \\
\hline${ }^{133} \mathrm{Cs}$ & 100.0 & $7 / 2$ & 52.468 & $-3 \times 10^{-3}$ & 269 & 15 \\
\hline${ }^{9} \mathrm{Be}$ & 100.0 & $3 / 2$ & 56.252 & $5.2 \times 10^{-2}$ & 78.8 & 3.6 \\
\hline${ }^{25} \mathrm{Mg}$ & 10.13 & $5 / 2$ & 24.480 & 0.22 & 1.54 & 284 \\
\hline${ }^{43} \mathrm{Ca}$ & 0.145 & $7 / 2$ & 26.912 & $-5 \times 10^{-2}$ & 0.0527 & 59 \\
\hline${ }^{87} \mathrm{Sr}$ & 7.02 & $9 / 2$ & 17.344 & 0.36 & 1.07 & 16200 \\
\hline${ }^{135} \mathrm{Ba}$ & 6.59 & $3 / 2$ & 39.536 & 0.18 & 1.83 & 660000 \\
\hline${ }^{137} \mathrm{Ba}$ & 11.32 & $3 / 2$ & 44.452 & 0.28 & 4.41 & 1610000 \\
\hline
\end{tabular}

adapted from Refs. 1 and 2.

new areas for NMR investigations became accessable with the discovery of alkali anions ${ }^{23}$, the synthesis of alkali and alkaline earth intercalation compounds of fullerenes ${ }^{24-27}$, and studies on clay minerals used as catalysts in organic synthesis $^{28}$. Two Specialists Periodical Reports ${ }^{29,30}$ summarize regularily the literature on NMR investigations involving alkali and alkaline earth metals.

For high-resolution NMR in organometallic chemistry, especially ${ }^{6,7} \mathrm{Li}$, but to some extent also ${ }^{9} \mathrm{Be}$ and ${ }^{133} \mathrm{Cs}$ are the nuclides of choice, while NMR of the remaining nuclei in Table 1 is less common for a number of reasons. As already mentioned, line broadening as a result of fast quadrupole relaxation renders the measurement of chemical shifts difficult if not impossible. For the same reason, scalar spin-spin coupling, which forms the basis of many modern NMR experiments, is not resolved or is even absent due to purely ionic bonding or the existence of solvent separated ion pairs. The majority of NMR investigations is thus confined to chemical shift and relaxation studies. In addition, because of effective quadrupolar relaxation, most of the heavier nuclei are not expected to show nuclear Overhauser effects which have proved so important in the structural elucidation of organolithium compounds. Aside from ${ }^{1} \mathrm{H},{ }^{6,7} \mathrm{Li}$ NOE effects, only for ${ }^{133} \mathrm{Cs}$ NOE spectra have been reported ${ }^{31,32}$. Finally, from all organometallic systems of main group metals, the lithium compounds are by far the most important for synthetic applications, only rivaled in the field of carbon compounds by the Grignard reagents. Initial attempts to use ${ }^{25} \mathrm{Mg}$ NMR in this area met with success ${ }^{33-35}$, but have not initiated further efforts in this direction, despite reported improvements in the experimental technique ${ }^{36}$.

It is thus quite understandable, that from the viewpoint of structural research on organometallic systems ${ }^{6,7} \mathrm{Li}$ NMR is much more attractive. In addition to ${ }^{1} \mathrm{H},{ }^{6} \mathrm{Li}$ and ${ }^{1} \mathrm{H},{ }^{7} \mathrm{Li}$ nuclear Overhauser effects, ample spin-spin coupling between ${ }^{6,7} \mathrm{Li}$ and other nuclei like ${ }^{1} \mathrm{H},{ }^{13} \mathrm{C},{ }^{15} \mathrm{~N},{ }^{29} \mathrm{Si}$,

${ }^{31} \mathrm{P}$ etc. exists and opens the doors to Alices wonderland of modern one- and two-dimensional NMR. The following account, therefore, deals exclusively with selected topics from recent NMR investigations of lithiated systems, where small linewidths and scalar spin-spin coupling paves the way for experiments which lead to a deeper understanding of structure and bonding.

\section{Structure Determinations Via ${ }^{2} \mathbf{H}$-induced ${ }^{6}$ Li-NMR Isotope Shifts}

small is beautiful

NMR isotope effects are long known ${ }^{37}$, but it was only after the introduction of high-field instrumentation that these parameters, which are often in the ppb region, became generally accessible. They soon were recognized as interesting data in connection with research on structure and bonding ${ }^{38-41}$. If an atom ${ }^{n} \mathrm{X}$ is replaced by its heavier isotope ${ }^{m} \mathrm{X}(m>n)$, a NMR shift, $\Delta(\mathrm{Y})\left({ }^{m / n} \mathrm{X}\right)$ is observed for the nucleus $\mathrm{Y}$ which may be directly attached to ${ }^{m} \mathrm{X}$ or several bonds away. For one-bond effects the shift is exclusively to high field (low frequency), while isotope shifts induced over several bonds may have the opposite direction. Two 
illustrative examples for one-bond effects from the literature are shown in Fig. 1.

The reason for the isotope shift lies in the bond lengths changes associated with the isotopic replacement, which lead to a slightly shorter bond for the compounds with the heavier isotope (Fig. 2). This is due to the anharmonicity of the $\mathrm{X}-\mathrm{Y}$ bond potential and the lower zero-point vibrational energy of the ${ }^{m} \mathrm{X}-\mathrm{Y}$ as compared to the ${ }^{n} \mathrm{X}-\mathrm{Y}$ bond. This results in a shielding effect for $\mathrm{Y}$ but also for nuclei several bonds away. However, in the case of isotope shifts over more than one bond, the opposite sign (low-field or highfrequency shift) is often observed ${ }^{42}$.

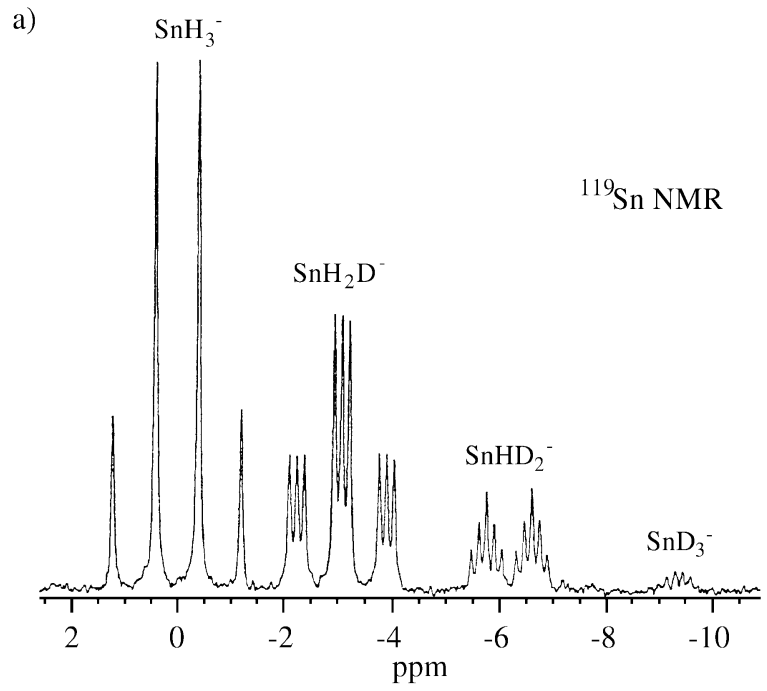

b)

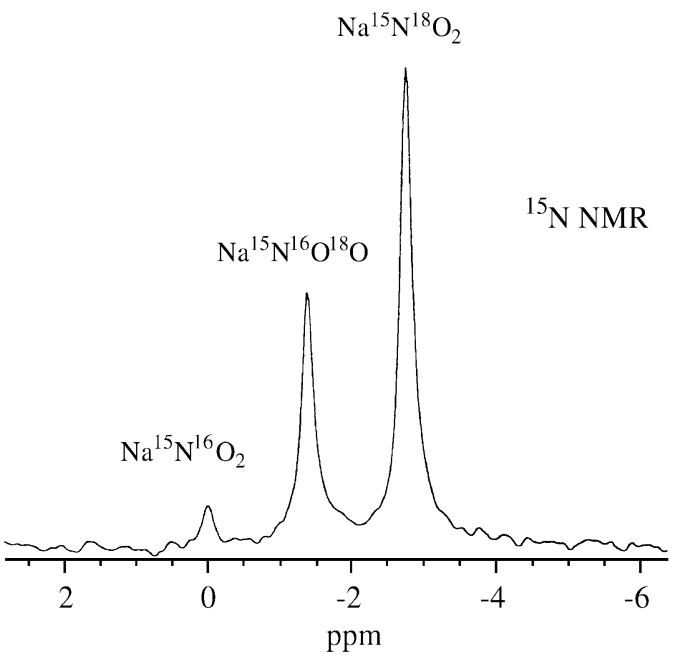

Figure 1. a) Deuterium-induced isotope shifts in the $134.2 \mathrm{MHz}{ }^{119} \mathrm{Sn}-$ NMR spectrum of tinhydrides $\mathrm{SnH}_{3-\mathrm{n}} \mathrm{D}_{\mathrm{n}}{ }^{-}(\mathrm{n} \leq 3)$ at $-50{ }^{\circ} \mathrm{C}$ in liquid ammonia; the isotope shifts $\Delta \delta$ per deuterium are $-3.1 \mathrm{ppm}$ (adapted from Wasylishen, R.E.; Burford, L. Can. J. Chem. 1987, 65, 2707): b) oxygen-induced isotope shifts in the $47.6 \mathrm{MHz}{ }^{15} \mathrm{~N}-\mathrm{NMR}$ spectrum of ${ }^{18} \mathrm{O}$ labeled sodium $\left[{ }^{15} \mathrm{~N}\right]$ nitrite $\left(95 \%{ }^{15} \mathrm{~N}, 77 \%{ }^{18} \mathrm{O}\right)$ in $50 \% \mathrm{D}_{2} \mathrm{O}$ (adapted from Risley, J.M.; Van Etten, R.L. NMR - Basic Principles and Progress, 1990, 22, 83).
In organic compounds, deuterium-induced shifts of ${ }^{13} \mathrm{C}$ resonances have been studied extensively and correlations with carbon hybridization and substitution ${ }^{43}$, hyperconjugation $^{44}$, dihedral angles ${ }^{45}$, and spin-spin coupling constants $^{46}$ were found. Apart from these aspects which are related to physical organic chemistry, isotope shifts have also been used in a straightforward way as assignment aids in ${ }^{13} \mathrm{C}-\mathrm{NMR}{ }^{47-49} \cdot{ }^{2} \mathrm{H} /{ }^{1} \mathrm{H}$ isotope shifts decrease with the number of bonds between deuterium and the ${ }^{13} \mathrm{C}$ nucleus which is observed and are usually too small to be detected if more than four bonds are involved. However, in unsaturated compounds effects over as much as twelve bonds have been reported ${ }^{50,51}$.

The isotopic fingerprint method which we introduced as a tool to study aggregation of organolithium compounds ${ }^{52}$ uses for the first time ${ }^{2} \mathrm{H}$-induced isotope shifts of ${ }^{6} \mathrm{Li}-\mathrm{NMR}$ signals. The idea was, that, for example in the case of a tetramer like methyllithium in diethylether, a 1:1 mixture of deuteriated and non-deuteriated material, $\mathrm{CD}_{3}{ }^{6} \mathrm{Li}$ and $\mathrm{CH}_{3}{ }^{6} \mathrm{Li}$, should yield different environments for the ${ }^{6} \mathrm{Li}$ nuclei. As shown in diagrams $\underline{1 \mathrm{a}}-\underline{1 \mathrm{~d}}$, the direct surrounding of a particular ${ }^{6} \mathrm{Li}$ nucleus might consist of three, two, one, or no $\mathrm{CH}_{3}$ group, leading to the environments $h h h, h h d, h d d$, and $d d d$. Considering the statistical distribution of the deuteriated ligand, a quadruplet with an intensity ratio of 1:3:3:1 was expected and indeed observed (Fig. 3). Here, the isotope shift amounts to roughly $16 \mathrm{ppb}$

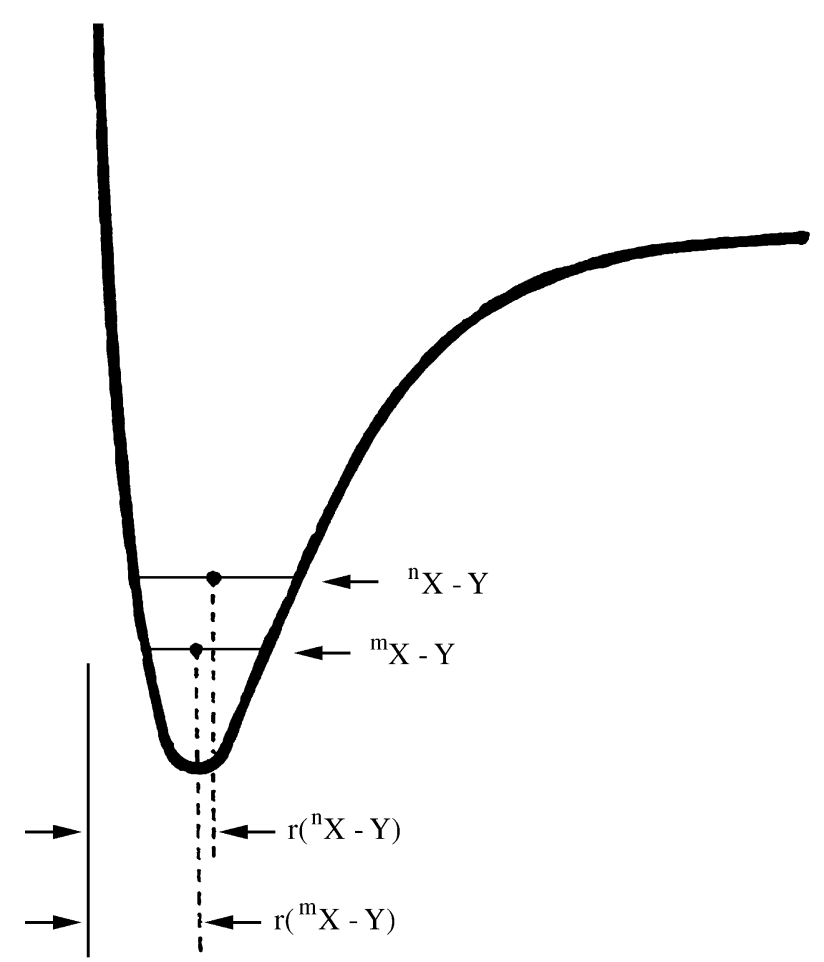

Figure 2. Schematic representation of an $\mathrm{X}-\mathrm{Y}$ bond potential for two isotopes of $\mathrm{X} ;{ }^{n} \mathrm{X}=$ light isotope; ${ }^{m} \mathrm{X}=$ heavy isotope. 


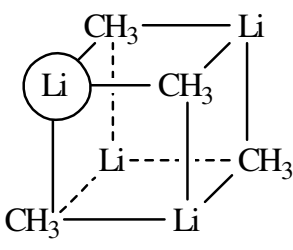

1a

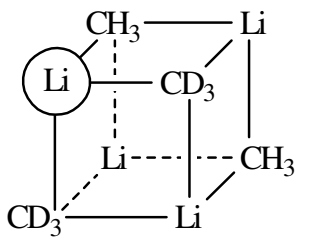

1c

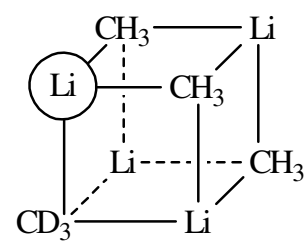

$1 \mathbf{b}$

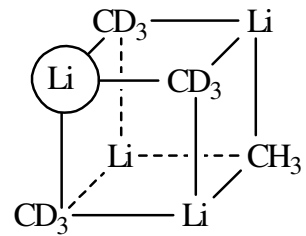

1d per $\mathrm{CD}_{3}$ group and is of positive sign on the $\delta$-scale (lowfield or high-frequency shift).

By a straightforward extension of this reasoning, a doublet is expected for a monomer and a triplet for a dimer (Fig. 4). Thus, clusters of different size are characterized by isotopic fingerprints, where the intensity ratio within the multiplets follows Pascal's triangle. In general, the number of observed lines is $n+1$ and the intensity distribution is given by the expression $(a+b)^{n}$, where $n$ is the number of organic ligands around each lithium cation and $a$ and $b$ are the mole fractions of ${ }^{2} \mathrm{H}$-labeled and non-labeled material, respectively.

The argument developed above takes into account only next neighbors and corresponds to the local environment approximation introduced by Brown. ${ }^{53}$ Indeed, ${ }^{2} \mathrm{H}$-induced isotope shifts from deuterons residing in organic ligands not directly attached to the ${ }^{6} \mathrm{Li}$ nucleus under study are mostly too small to be detected and have sofar been observed in simple alkyllithium compounds only in a few cases (see below). The remote neighbor thus normally does

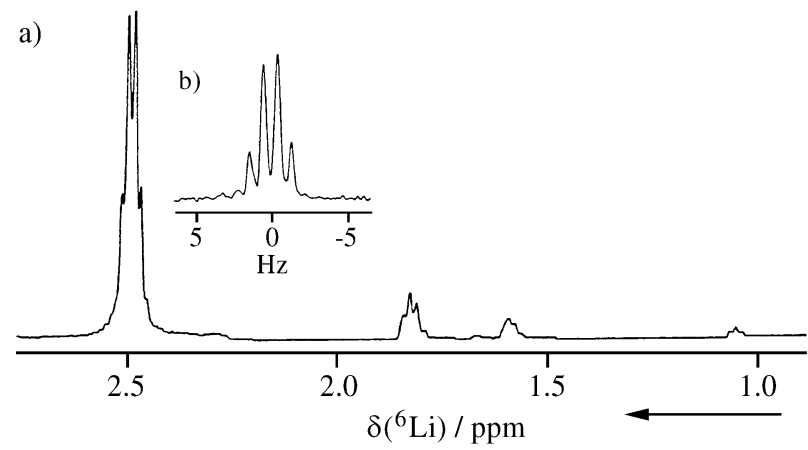

Figure 3. a) $58.9 \mathrm{MHz}{ }^{6} \mathrm{Li}-\mathrm{NMR}$ spectrum of an equimolar mixture of $\mathrm{CH}_{3} \mathrm{Li} / \mathrm{CD}_{3} \mathrm{Li}$ in $\left[\mathrm{D}_{10}\right]$ diethylether at $161 \mathrm{~K}$ with inverse-gated ${ }^{1} \mathrm{H}$-decoupling in order to remove line broadening due to scalar ${ }^{1} \mathrm{H},{ }^{6} \mathrm{Li}$ coupling and intensity changes caused by ${ }^{1} \mathrm{H},{ }^{6} \mathrm{Li}$ nuclear Overhauser effects; $\mathrm{b}$ ) resolution enhanced isotopic fingerprint of the ${ }^{6} \mathrm{Li}$ resonance. a)<smiles>CN1C2(C)CCC1(C)C(C)(c1ccccc1)N2C</smiles>

${ }^{6} \mathrm{Li}-\mathrm{NMR}$

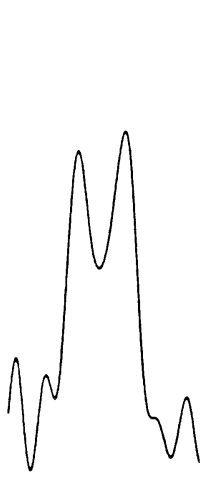

$1: 1$ b)

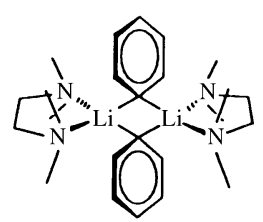

c)

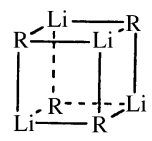

Figure 4. Deuterium-induced isotopic fingerprints in ${ }^{6} \mathrm{Li}-\mathrm{NMR}$ spectra of partially deuteriated organolithium aggregates; a) phenyllithium monomer (THF/pentamethyldiethylenetriamine, $151 \mathrm{~K})$; b) phenyllithium dimer $\left(\mathrm{Et}_{2} \mathrm{O} /\right.$ tetramethylethylenediamine, $\left.162 \mathrm{~K}\right)$; c) methyllithium tetramer $\left(\mathrm{R}=\mathrm{CH}_{3}\right)\left(\mathrm{Et}_{2} \mathrm{O}, 181 \mathrm{~K}\right)$; the measured ${ }^{2} \mathrm{H} /{ }^{1} \mathrm{H}$ isotope shifts for $\delta\left({ }^{6} \mathrm{Li}\right)$ are $19.2,10.4$, and $15.6 \mathrm{ppb}$, respectively. All systems were ${ }^{6} \mathrm{Li}$ labeled and $50 \%$ of the organic ligands were perdeuteriated; $v_{\mathrm{o}}\left({ }^{6} \mathrm{Li}\right)=$ $58.9 \mathrm{MHz}$.

not effect the lithium resonance as long as we deal with aggregates which are static on the NMR time scale. Considering the magnitude of the shift effect ( $16 \mathrm{ppb}$ or $0.9 \mathrm{~Hz}$ at $58.88 \mathrm{MHz}$ for ${ }^{6} \mathrm{Li}$ on a $400 \mathrm{MHz}{ }^{1} \mathrm{H}$ instrument), the lifetime of the particular cluster should be in the order of 2 $\mathrm{s}$ or more. If the lifetime falls short of this limit, intra-aggregate exchange brings also the remote neighbors into play and for a tetramer, again with equal numbers of deuteriated and non-deuteriated ligands, five different environments exist: $h h h h, h h h d, h h d d, h d d d$, and $d d d d$. Now a quintuplet results, as observed for the fluxional phenyllithium tetramer (Fig. 5a).

Finally, with the inset of inter-aggregate exchange, line broadening starts and a singlet is found in the fast exchange limit (Fig. 5).

An advantage of the isotopic fingerprint method as compared to other NMR techniques which are used to study aggregation phenomena and which rely on the measurement of ${ }^{13} \mathrm{C}$ spectra (chemical shift studies, observation of ${ }^{13} \mathrm{C}$, ${ }^{6} \mathrm{Li}$ scalar spin-spin coupling) is its high sensitivity due to double isotopic enrichment, which is easily achieved. ${ }^{6} \mathrm{Li}$ is readily incorporated directly or via lithiation with [ ${ }^{6} \mathrm{Li}$ ]butyllithium, while numerous procedures for the deuteriation of organic ligands are available. Thus, even aggre- 


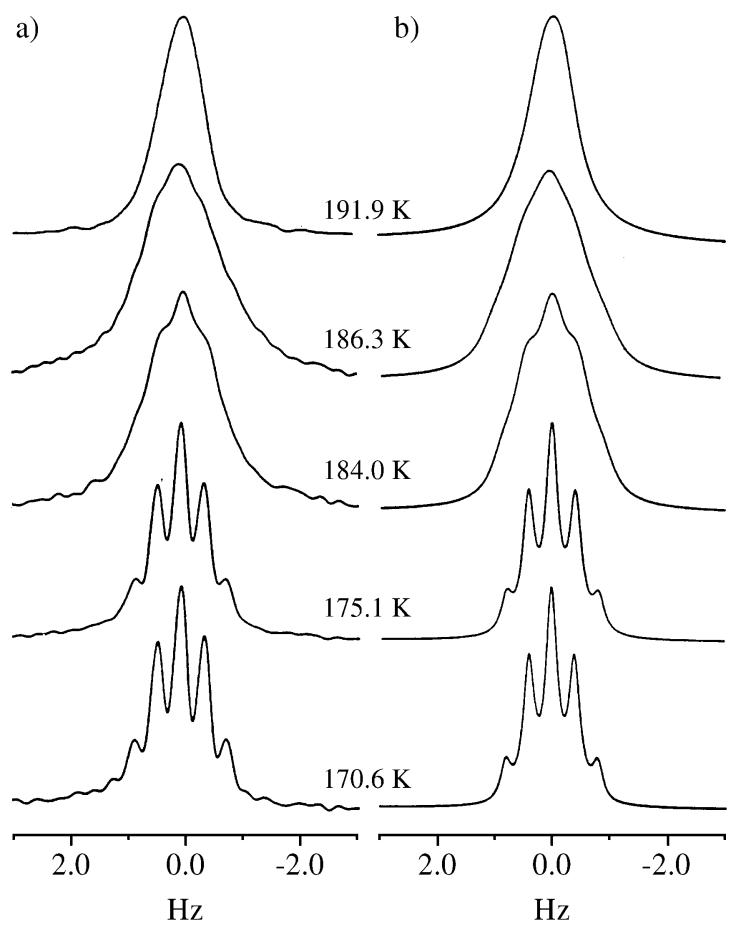

Figure 5. ${ }^{1} \mathrm{H}$ decoupled $58.9 \mathrm{MHz}{ }^{6} \mathrm{Li}-\mathrm{NMR}$ spectrum of $\mathrm{C}_{6} \mathrm{H}_{5} \mathrm{Li} / \mathrm{C}_{6} \mathrm{D} 5 \mathrm{Li}$ (1:1) $0.5 \mathrm{M}$ in [ $\left.\mathrm{D}_{10}\right]$ diethylether at various temperatures; left experimental, right calculated.

gates which coexist in low concentration may be detected and characterized ${ }^{54}$.

In order to illustrate the application of the isotopic fingerprint method further, we discuss below recent findings for lithiated cyclopropyl compounds and results of a study on the structure of mixed aggregates between methyllithium and lithium salts.

\section{Aggregation behavior of}

\section{1-Lithio-trans-2,3-dimethyl-cyclopropane}

For a study of cyclopropyllithium compounds we chose the trans-2,3-dimethyl system $\underline{\mathbf{2}}$ which was synthesized from the corresponding bromide $\underline{\mathbf{3}}$, obtained by tributyltinhydride reduction of the 1,1-dibromide $\underline{4}$, which in turn resulted from the addition of dibromocarbene to trans-2butene. A salt-free sample was prepared via the mercury compound $\underline{\mathbf{5}}$. Deuterium at C-1 was introduced by reduction of the dibromide with tributyltindeuteride.

For the ${ }^{6} \mathrm{Li}-\mathrm{NMR}$ investigation of the aggregation behavior, a sample of $\underline{\mathbf{2}}$ and $[\mathrm{D}] \underline{\mathbf{2}}(1: 1)$ in diethylether/THF (1:1) and one mole equivalent $\mathrm{LiBr}$ was prepared, which showed a ${ }^{6} \mathrm{Li}$ doublet $(\Delta \delta=4 \mathrm{ppb})$ indicating the formation of a mixed dimer $\left[\mathrm{C}_{5} \mathrm{H}_{9} \mathrm{Li}, \mathrm{LiBr}\right]$ (Fig. 6a). The observed multiplicity is also compatible with the presence of the monomeric lithium species $\underline{\mathbf{2}}$, but in this case a separate ${ }^{6} \mathrm{Li}$ signal for $\mathrm{LiBr}$ should have been observed. The sole resonance at $0.8 \mathrm{ppm}$ (rel. to $0.1 \mathrm{M}$ ext. $\mathrm{LiBr}$ in THF) is thus due to the mixed dimer. This finding contrasts with the

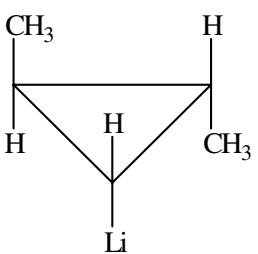

2

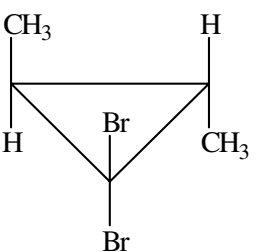

4

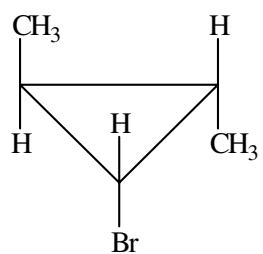

3

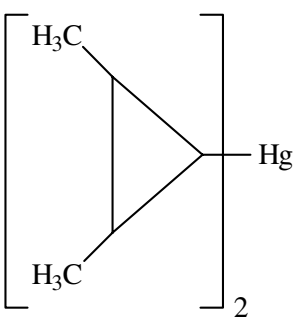

5 observation made for the unsubstituted parent compound cyclopropyllithium, where a mixed tetramer, $\left[\left(\mathrm{C}_{3} \mathrm{H}_{5} \mathrm{Li}\right)_{2},(\mathrm{LiBr})_{2}\right]$, has been found in the crystal ${ }^{55}$ and in diethylether/THF solution ${ }^{56}$.

The two-dimensional ${ }^{1} \mathrm{H},{ }^{6} \mathrm{Li}$ HOESY spectrum ${ }^{57}$ (Fig. 6b) established nuclear Overhauser effects between ${ }^{6} \mathrm{Li}$ and $\mathrm{H}(1)$ as well as $\mathrm{H}(2)$, but cross peaks between ${ }^{6} \mathrm{Li}$ and $3-\mathrm{CH}_{3}$ were not observed. This may be due to steric repulsion between the methyl group and the lithium double bridge which increases the $\mathrm{Li}_{-} \mathrm{CH}_{3}$ distance.

For a salt-free sample of $\underline{\mathbf{2}}$ and [D] $\underline{\mathbf{2}}$ (1:1), prepared via the mercury compound $\underline{\mathbf{5}}$ in the same solvent mixture, ${ }^{6} \mathrm{Li}$ triplet, which characterizes a dimer, $(\underline{\mathbf{2}})_{2}$, is observed at $187 \mathrm{~K}$ as the dominating signal (Fig. 7a). Interesting lineshape changes are, however, found at lowering the temperature to $161 \mathrm{~K}$. The structure of the ${ }^{6} \mathrm{Li}$ signal resembles a quadruplet between 170 and $163 \mathrm{~K}$, which is associated with a tetramer. Tetramer formation is, however, rather unlikely considering the relatively modest and steady change in chemical shift which is much better explained by a normal temperature gradient rather than by a change of aggregation state. A ${ }^{6} \mathrm{Li}-\mathrm{NMR}$ spectrum run at $73.5 \mathrm{MHz}$ (500 MHz ${ }^{1} \mathrm{H}$ instrument) revealed that two overlapping triplets are present at $161 \mathrm{~K}$ which deceived a quadruplet at lower field strength (Fig. 7b). Thus, two dimers are present in a ratio of $1.0: 0.7$, a consequence of the chirality of the monomer $\underline{\mathbf{2}}$ which forms diastereomeric dimers of the $(\mathrm{R}, \mathrm{S}) ;(\mathrm{S}, \mathrm{R})$ and $(\mathrm{R}, \mathrm{R}) ;(\mathrm{S}, \mathrm{S})$ type, respectively.

From the intensity ratio of the signals one calculates $\mathrm{K}=0.48$ and $\Delta \mathrm{G}^{\mathrm{o}}=1.1 \mathrm{~kJ} / \mathrm{mol}$ at $163 \mathrm{~K}$, but it is not known which of the two diastereomers is the more stable one. It is interesting, however, that NOE effects are found between ${ }^{6} \mathrm{Li}$ and $\mathrm{H}(2)$ as well as $3-\mathrm{CH}_{3}$ in these dimers (Fig. 7c) which indicates that their structure, as far as the orientation of the lithium double bridge with respect to the three-mem- 
bered rings is concerned, differs from that of the mixed dimer containing $\mathrm{LiBr}$. In the ${ }^{1} \mathrm{H}$ spectrum the signals for the diastereomers are not separated and it is not clear if the NOE effects result from the $d, l$ or the meso compounds or if both are responsible.

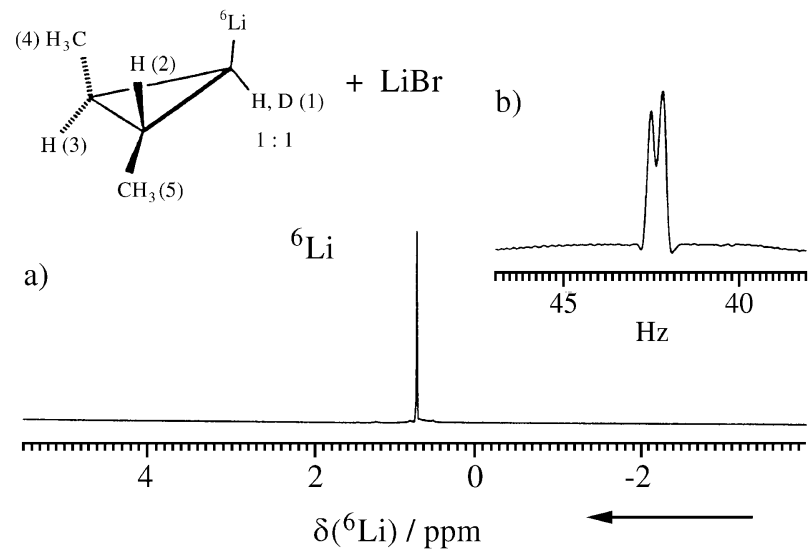

c)

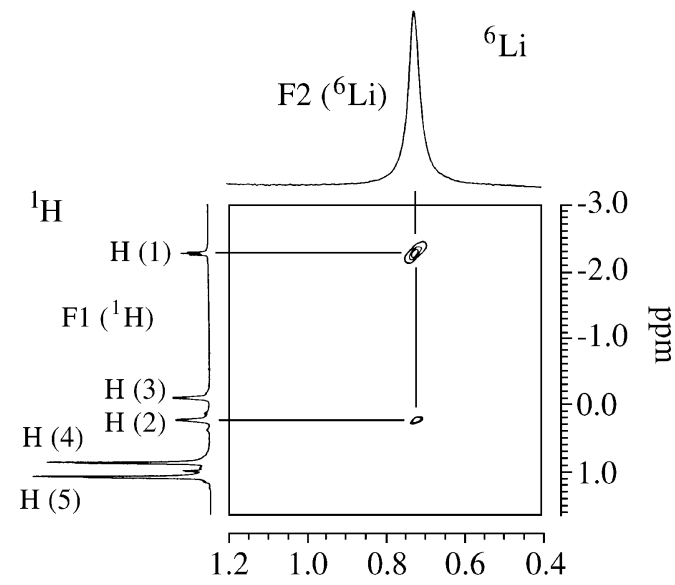

Figure 6. a) $58.9 \mathrm{MHz}{ }^{6} \mathrm{Li}-\mathrm{NMR}$ spectrum of a mixture of the deuteriated and non-deuteriated 1-lithio-trans-2,3-dimethylcyclopropane (2) and $\operatorname{LiBr}(1: 1: 2) 0.2 \mathrm{M}$ in [D10]diethylether/[D8]THF (7:3) at $178 \mathrm{~K}$; b) resolution enhanced isotopic fingerprint for the signal in spectrum a; isotope shift $0.25 \mathrm{~Hz}=4.2 \mathrm{ppb}$; c) two-dimensional nuclear Overhauser (HOESY) spectrum of $2 /[1-\mathrm{D}] 2 / 2 \mathrm{LiBr}$ showing crosspeaks between ${ }^{6} \mathrm{Li}$ and $\mathrm{H}(1)$ and $\mathrm{H}(2)$.
Quite a different picture emerged from measurements of the salt-free sample of $\underline{\mathbf{2}}$ in diethylether as the sole solvent. The ${ }^{6} \mathrm{Li}$ spectrum now shows three signals at 2.02, 2.08, and $2.22 \mathrm{ppm}$ of comparable intensity (1.15: 1.23 : 1.00). The isotopic fingerprint method yielded a doublet, a triplet, and a quintuplet which characterizes these signals as belonging to the monomer, the dimer, and a fluxional tetramer (Fig. 8). The coexistence of these three different aggregates is unique and apparently a consequence of comparable energies for solvation of the lithium cation with the solvent and the organic ligand.

\section{Mixed aggregate formation between Methyllithium and Lithium salts}

NMR studies of mixed aggregate formation between alkyllithium compounds and lithium salts often suffer from low sensitivity of ${ }^{13} \mathrm{C}$ measurements if the concentration of certain clusters falls below $0.1 \mathrm{M}$. Here, the isotopic fingerprint method with its high isotopic enrichment can be used to advantage. We investigated methyllithium in the presence of $\mathrm{LiI}$ and $\mathrm{LiBr}$, systems studied earlier by Brown ${ }^{58}$ and $\mathrm{Waak}^{59}$ by ${ }^{7} \mathrm{Li}$ chemical shift measurements.

In the case of the $\mathrm{CH}_{3} \mathrm{Li} / \mathrm{LiI}$ system ${ }^{52}$, five ${ }^{6} \mathrm{Li}$ resonances were observed in the slow exchange limit at $178 \mathrm{~K}$, four of which give rise to typical fingerprints which characterize the ${ }^{6} \mathrm{Li}$ environment in the different aggregates; the signal at highest field is due to LiI (Fig. 9). The assigments based on signal multiplicity were confirmed by NOE measurements for a non-deuteriated sample, where a constant intensity increase per $\mathrm{CH}_{3}$ neighbor was found. This result also agrees with the observation of four signals in the ${ }^{1} \mathrm{H}-\mathrm{NMR}$ spectrum.

From an analysis of the measured intensity distribution and the observed ${ }^{1} \mathrm{H},{ }^{6} \mathrm{Li}$ NOE effects, the presence of aggregates $\mathrm{Li}_{4}\left(\mathrm{CH}_{3}\right)_{4}(\underline{\mathbf{6}}), \mathrm{Li}_{4}\left(\mathrm{CH}_{3}\right)_{3} \mathrm{I}(\underline{\mathbf{7}}), \mathrm{Li}_{4}\left(\mathrm{CH}_{3}\right)_{2} \mathrm{I}_{2}(\underline{\mathbf{8}})$, and $\mathrm{Li}_{4}\left(\mathrm{CH}_{3}\right) \mathrm{I}_{3}(\underline{\mathbf{9}})$ was derived. Due to facile crystallisation of cluster $\underline{\mathbf{8}}$ and LiI, instead of a statistical distribution only a non-equilibrium distribution of the aggregates was observed which did not allow to calculate energy differences on the basis of signal integration.

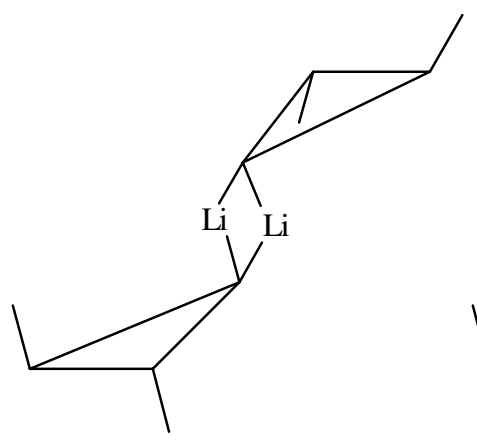

(S,S)

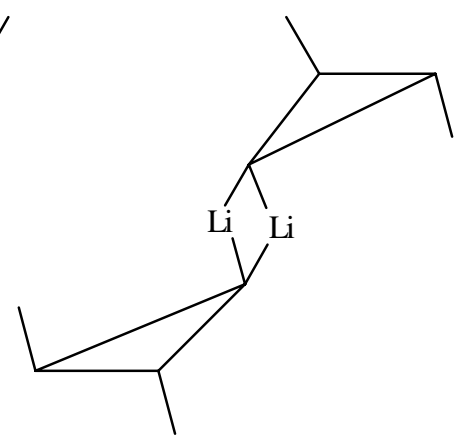

$(\mathrm{S}, \mathrm{R})$

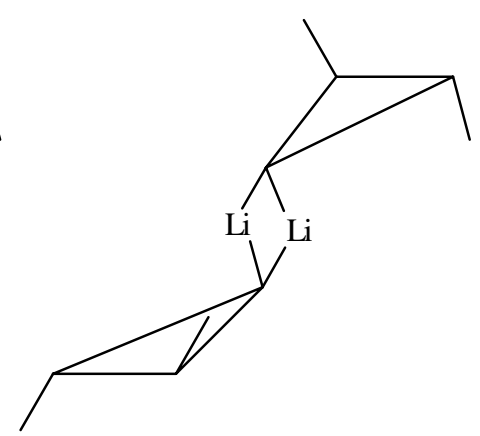

$(\mathrm{R}, \mathrm{R})$ 
(4) $\mathrm{H}_{3} \mathrm{C}$
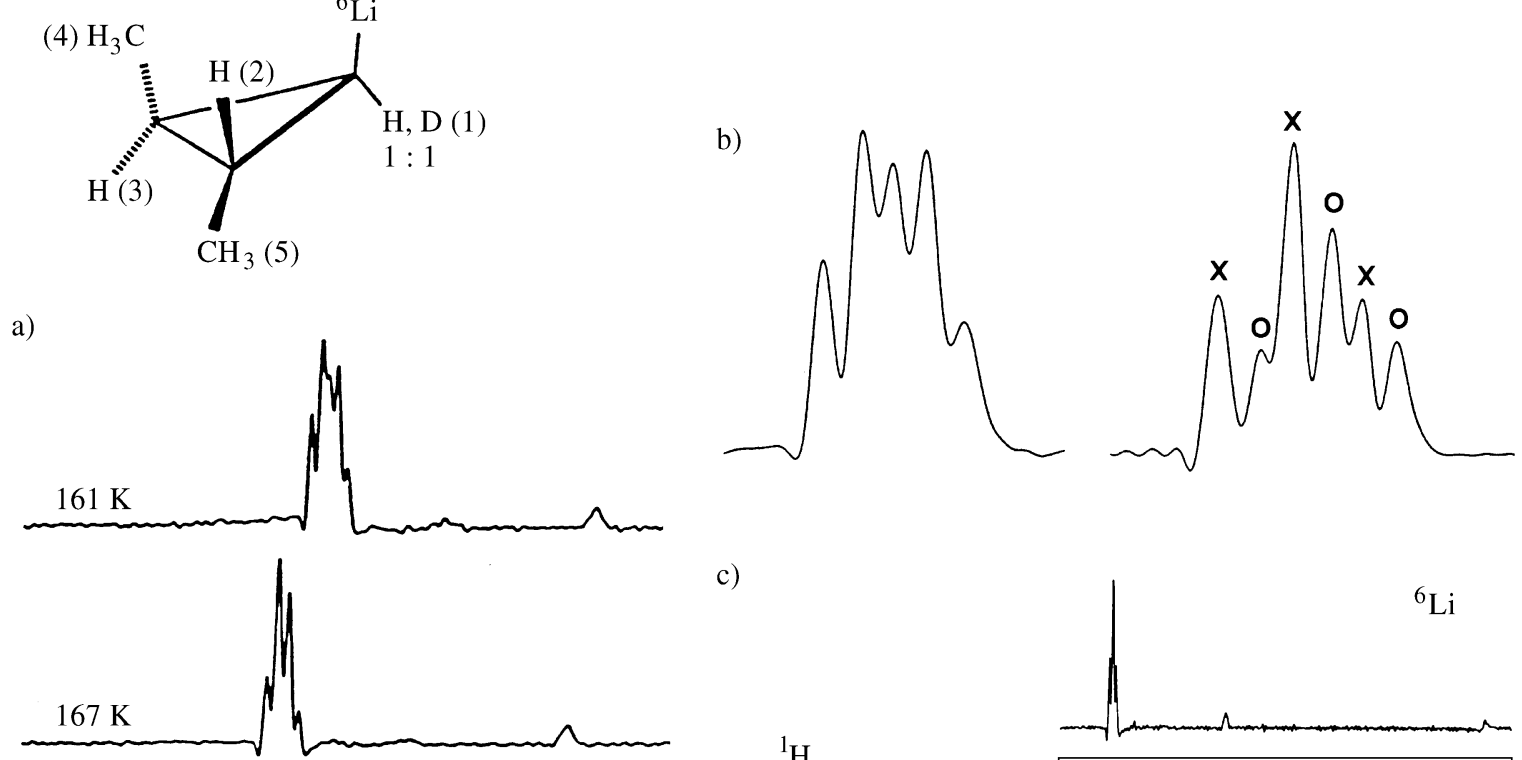

c)
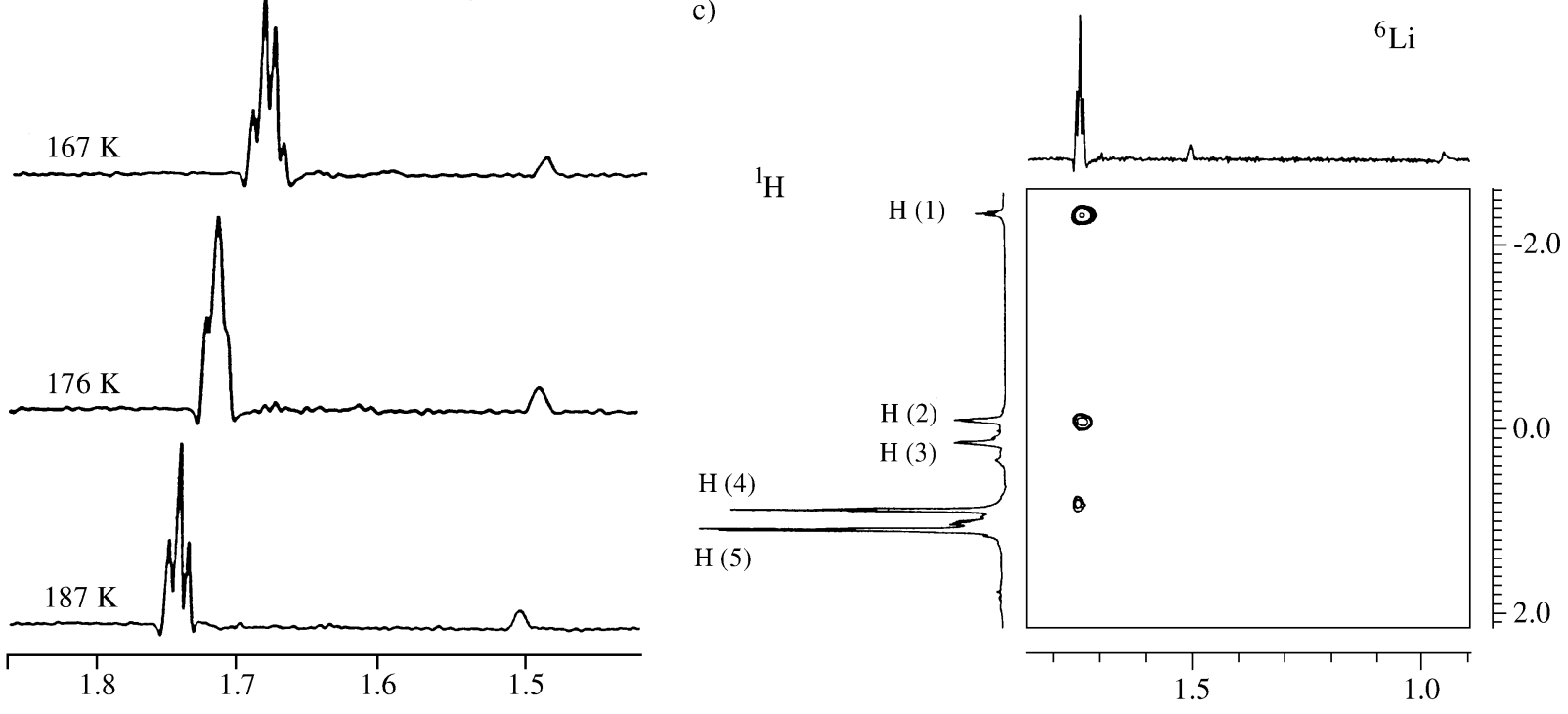

Figure 7. a) Temperature dependence of the $58.9 \mathrm{MHz}{ }^{6} \mathrm{Li}-\mathrm{NMR}$ spectrum of an equimolar salt-free mixture of deuteriated and non-deuteriated 1-lithio-trans-2,3-dimethylcyclopropane (2) $0.2 \mathrm{M}$ in [D10]diethylether/[D8]THF (7:3); b) the same signal at 58.9 (left) and $73.6 \mathrm{MHz}$ (right) enlarged showing the overlap of two triplets of unequal intensity; c) two-dimensional nuclear Overhauser (HOESY) spectrum of 2/[1-D]2 at 179 K showing crosspeaks between ${ }^{6} \mathrm{Li}$ and $\mathrm{H}(1), \mathrm{H}(2)$, and $3-\mathrm{CH}_{3}(\mathrm{H}-4)$.

A similar study of the system $\mathrm{CH}_{3} \mathrm{Li} / \mathrm{LiBr}$ in diethylether yielded the ${ }^{6} \mathrm{Li}-\mathrm{NMR}$ spectra shown in Fig. 10a, where the NOE difference experiment (Fig. 10b) identifies those lithium sites which are adjacent to at least one $\mathrm{CH}_{3}$ group. This leaves a total of five signals, centred at three different chemical shift values $(0.44,1.04 / 1.08$, 1.72/1.80 ppm rel. to $\mathrm{LiBr}$ ).

The measured NOE effects suggested next neighbor environments $\left[\mathrm{CH}_{3} \mathrm{BrBr}\right], \quad\left[\mathrm{CH}_{3} \mathrm{CH}_{3} \mathrm{Br}\right]$, and $\left[\mathrm{CH}_{3} \mathrm{CH}_{3} \mathrm{CH}_{3}\right]$ for these ${ }^{6} \mathrm{Li}$ resonances and this is borne out by the isotopic fingerprints observed for a sample of composition $\mathrm{CH}_{3} \mathrm{Li} / \mathrm{CD}_{3} \mathrm{Li} / \mathrm{LiBr}$ (1:1:2) (Fig. 10c): there is a doublet for signal 2, two triplets for signals 3 and 4 , and two quadruplets for signals 5 and 6 . As in the case of the iodine containing clusters, we can distinguish the ${ }^{6} \mathrm{Li}$ resonances with the environments $\left[\mathrm{LiCH}_{3} \mathrm{CH}_{3} \mathrm{CH}_{3}\right] \mathrm{CH}_{3}$ (signal 5) and $\left[\mathrm{LiCH}_{3} \mathrm{CH}_{3} \mathrm{CH}_{3}\right] \mathrm{X}$ (signal 6) with $\mathrm{X}=\mathrm{Br}$ in the present case, but compared to the iodine case the chemical shift order for these two aggregates is reversed. Furthermore, we have here different signals for $\left[\mathrm{LiCH}_{3} \mathrm{CH}_{3} \mathrm{Br}\right] \mathrm{CH}_{3}$ and $\left[\mathrm{LiCH}_{3} \mathrm{CH}_{3} \mathrm{Br}\right] \mathrm{Br}$. As shown by the highly resolved spectrum of the two triplets around 1.06 $\mathrm{ppm}$, there is a small doublet splitting of $0.24 \mathrm{~Hz}$ for each line of the triplet corresponding to $\left[\mathrm{LiCH}_{3}, \mathrm{CH}_{3} \mathrm{Br}\right] \mathrm{CH}_{3}$ (Fig. 10d). Thus, an isotope effect of $4.1 \mathrm{ppb}$ from the remote $\mathrm{CD}_{3}$ group is present. The analysis of the signal 
a)
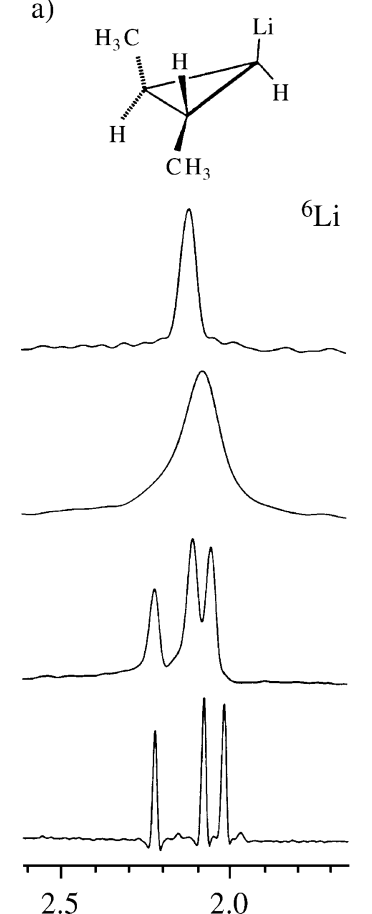

2.5

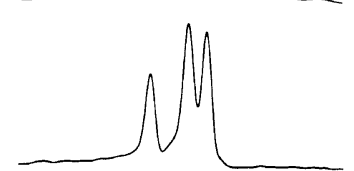

b)
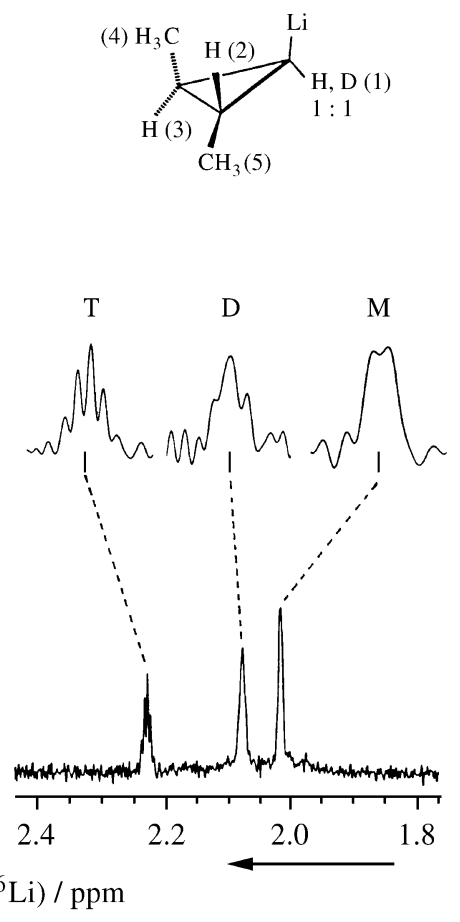

Figure 8. a) $58.9 \mathrm{MHz}{ }^{6} \mathrm{Li}$-NMR spectra of 1-lithio-trans-2,3-dimethylcyclopropane $0.2 \mathrm{M}$ in $\left[\mathrm{D}_{10}\right]$ diethylether at various temperatures; $\mathrm{b}$ ) isotopic fingerprints for the ${ }^{6} \mathrm{Li}-\mathrm{NMR}$ signals shown in a) from an equimolar mixture of deuteriated and non-deuteriated $2(\mathrm{~T}=$ tetramer, $\mathrm{D}=$ dimer, $\mathrm{M}=$ monomer).

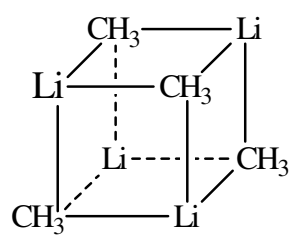

6

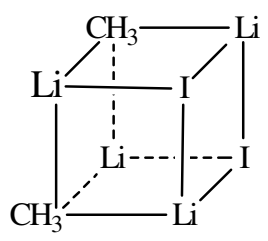

8

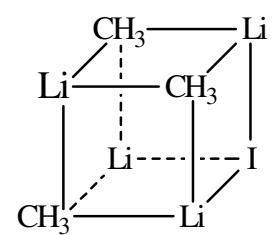

7

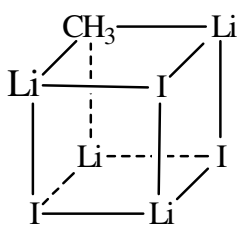

9 intensities, the splitting patterns as well as the NOE effects shows that apart from the tetramer $\mathbf{6}$ (signal 5) the mixed aggregates $\underline{\mathbf{1 0}}$ (signals 4 and 6 ) and $\underline{\mathbf{1 1}}$ (signals 2 and 3 ) are present.

There is no clear indication of the presence of a significant concentration of cluster $\underline{\mathbf{1 2}}$ which should yield a dou-
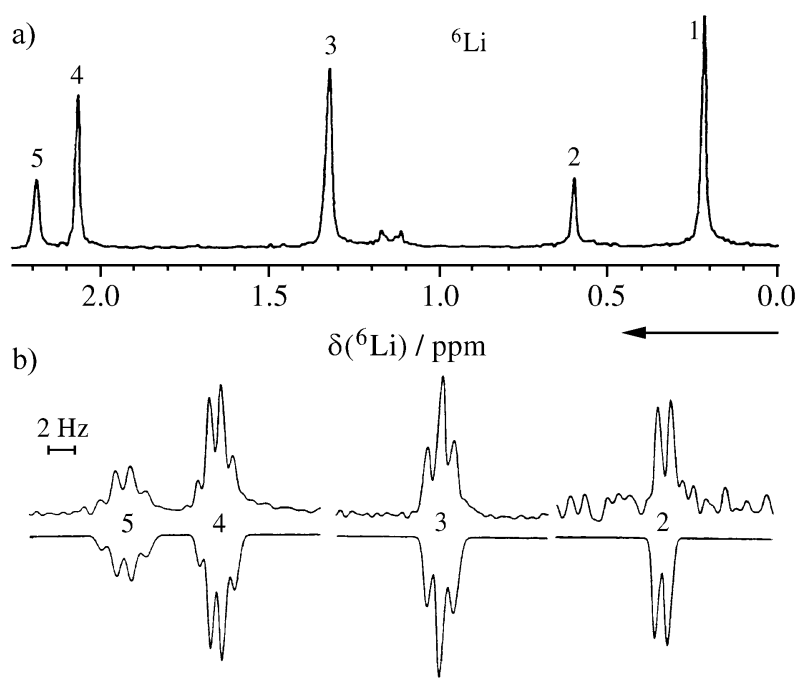

Figure 9. a) $58.9 \mathrm{MHz}^{6} \mathrm{Li}-\mathrm{NMR}$ spectrum of a mixture of $\mathrm{CH}_{3} \mathrm{Li}$ and $\mathrm{LiI}$ $(1: 1)$ in $\left[\mathrm{D}_{10}\right]$ diethylether at $178 \mathrm{~K}$; b) isotopic fingerprints observed for the signals shown in a) using an equimolar mixture of $\mathrm{CH}_{3} \mathrm{Li} / \mathrm{CD}_{3} \mathrm{Li}$ and two equivalents of LiI.

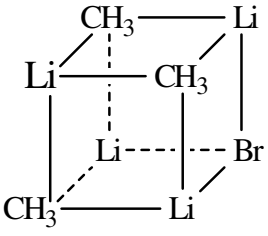

10

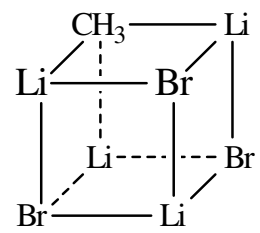

12

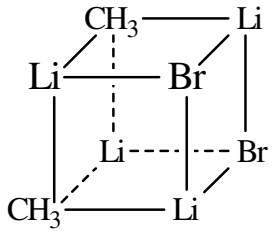

11 blet as its isotopic fingerprint. A number of smaller lines around $0.3 \mathrm{ppm}$, which indeed yield doublets in spectrum c), are unidentified and may come from this source. The ${ }^{6} \mathrm{Li}$ resonance of the $\mathrm{Li}[\mathrm{BrBrBr}]$ environment could coincide with the $\mathrm{LiBr}$ signal at $0 \mathrm{ppm}$.

If THF is used as the sole solvent, dramatic changes in the number of lines and their intensities as well as multiplicities are observed (Fig. 11). Cluster $\mathbf{6}$ (signal 5) is now the dominating species with a small contribution of $\underline{\mathbf{1 0}}$ (signals 3 and 4). Again a long range isotope effect is observed for environment $\left[\mathrm{LiCH}_{3} \mathrm{CH}_{3}, \mathrm{Br}\right] \mathrm{CH}_{3}$ (Fig. 11c). A doublet at $0.73 \mathrm{ppm}$ in spectrum b) (signal 2) indicates the presence of a next neighbor environment $\left[\mathrm{CH}_{3} \mathrm{BrBr}\right]$. This cannot, however, originate from cluster 11, because this would require another signal of the same intensity at 


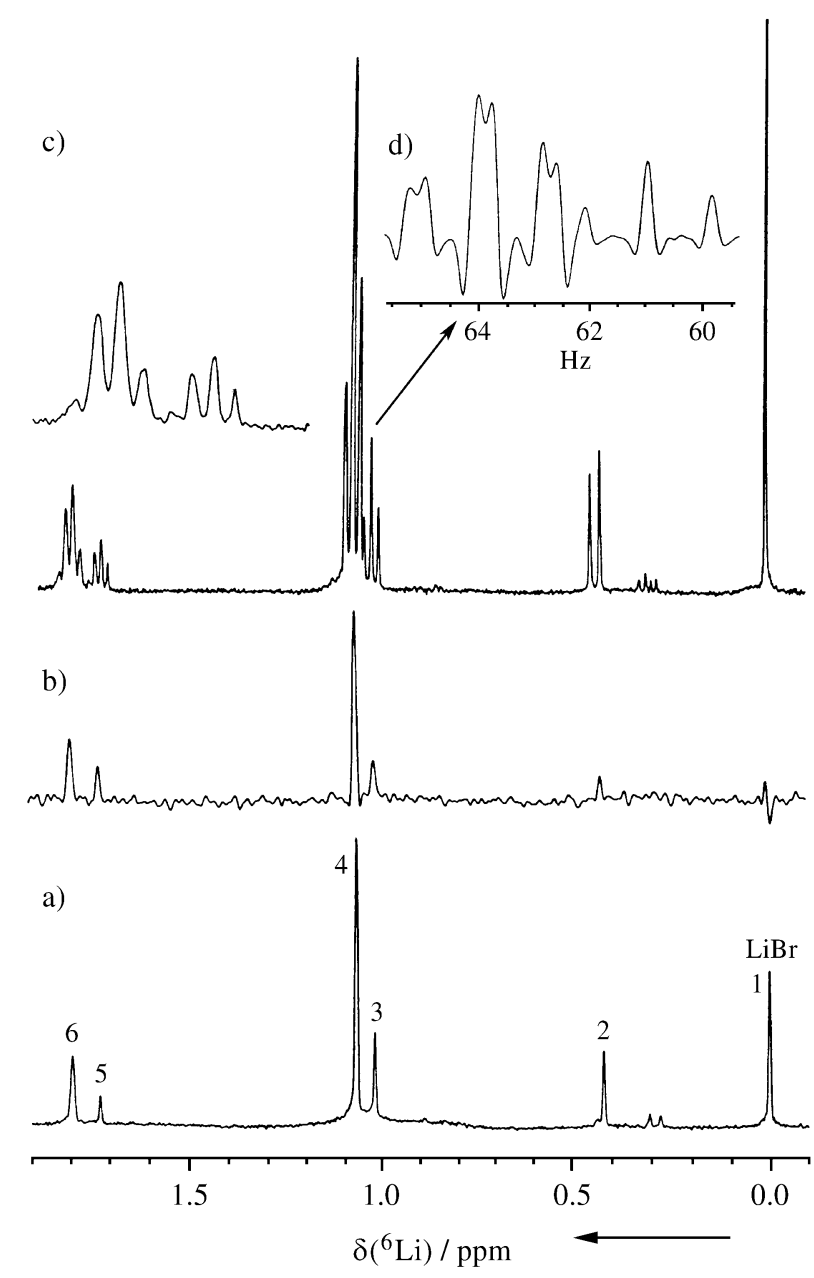

Figure 10. a) $58.9 \mathrm{MHz}{ }^{6} \mathrm{Li}-\mathrm{NMR}$ spectrum of $\mathrm{CH}_{3} \mathrm{Li}$ in the presence of $\operatorname{LiBr}(1: 1)$ in [ $\left.\mathrm{D}_{10}\right]$ diethylether at $183 \mathrm{~K}$; b) nuclear Overhauser difference spectrum of a); c) isotopic fingerprints for an equimolar mixture of $\mathrm{CH}_{3} \mathrm{Li} / \mathrm{CD}_{3} \mathrm{Li}$ and two moles of $\mathrm{LiBr}$ under the same conditions as in a); d) highly resolved signals at 1.0-1.1 ppm showing doublet splitting due to an additional isotope shift for the low-field triplet.

ca. $1.1 \mathrm{ppm}$ for the next neighbor combination $\left[\mathrm{CH}_{3} \mathrm{CH}_{3} \mathrm{Br}\right]$. An interesting information as to the origin of this signal comes from the dynamic behavior of the ${ }^{6} \mathrm{Li}$ spectrum, which shows coalescence between this doublet with the singlet of $\mathrm{LiBr}$ while the remaining resonances are virtually unaffected (Fig. 12). The doublet thus arises from a mixed dimer $\underline{\mathbf{1 3}}$. This is nicely born out by the ${ }^{13} \mathrm{C}-\mathrm{NMR}$ spectrum, which shows in addition the the septuplet of the tetramer $\underline{\mathbf{6}}(J=5.7 \mathrm{~Hz})$ a quintuplet with $J=9.8 \mathrm{~Hz}$, compatible with a dimer (Fig. 12b).

Compared to the results of the earlier investigations ${ }^{58,59}$, which were based on the temperature and concentration dependence of the ${ }^{7} \mathrm{Li}$ chemical shifts, the isotopic fingerprint method thus established the additional existence of aggregates $\underline{\mathbf{8}}, \underline{\mathbf{9}}$ and $\underline{\mathbf{1 3}}$.
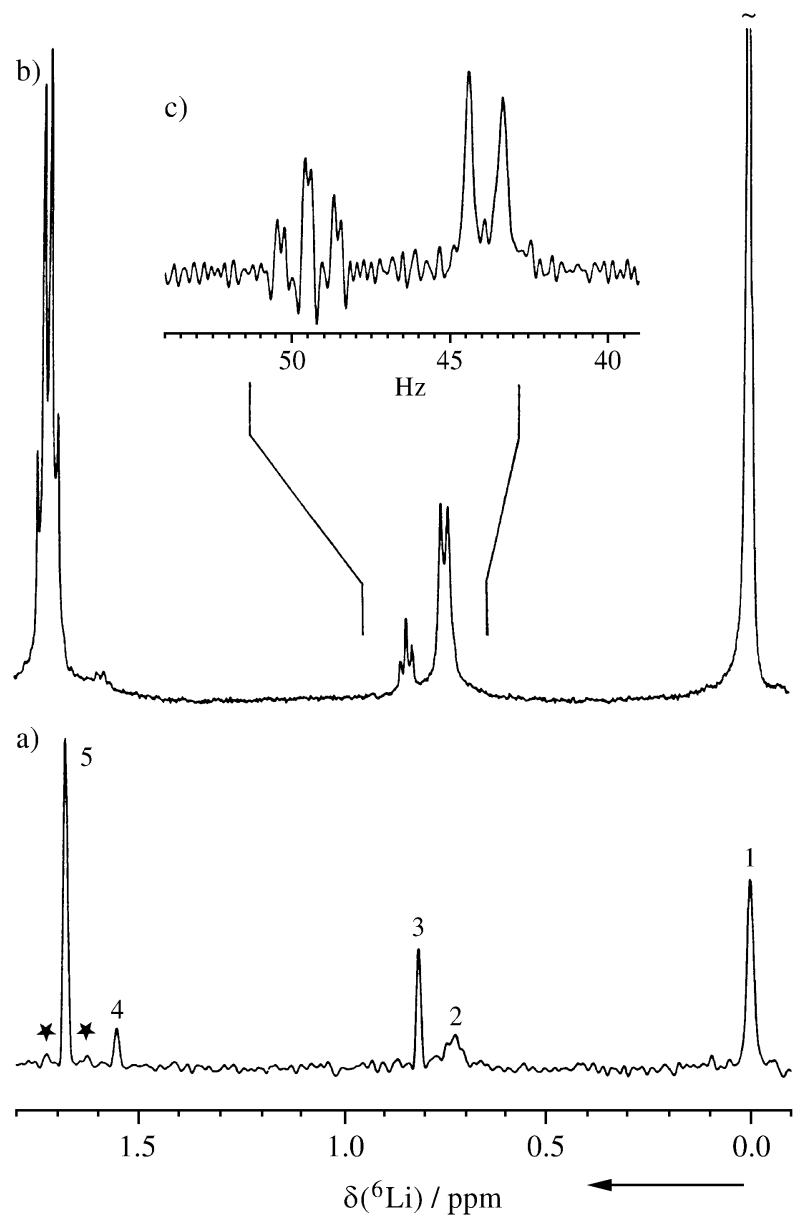

Figure 11. a) $58.9 \mathrm{MHz}{ }^{6} \mathrm{Li}-\mathrm{NMR}$ spectrum of $\mathrm{CH}_{3} \mathrm{Li}$ in the presence of $\mathrm{LiBr}(1: 1)$ in [D8] THF at $183 \mathrm{~K}$; b) isotopic fingerprints for an equimolar mixture of $\mathrm{CH}_{3} \mathrm{Li} / \mathrm{CD}_{3} \mathrm{Li}$ and two moles of $\mathrm{LiBr}$ under the same conditions as in a); c) highly resolved signals at 0.7-0.9 ppm showing an additional isotope shift for the low-field triplet.

\section{One- and Two-Dimensional NMR Experiments Based on Scalar Spin-Spin Coupling and Nuclear Overhauser Effects}

Two-D or not Two-D

Scalar spin-spin coupling is one of the fundamental NMR phenomena for chemical structure determinations and lends color to the otherwise rather dull singlet spectra of uncoupled spins. Even more important, scalar interactions form the basis for numerous one- and two-dimensional experiments which yield information on atomic connectivities in a given molecular structure.

In the case of organolithium compounds, the magnitude of spin-spin coupling involving lithium strongly depends on the coupling partner, with fairly large values $(>2 \mathrm{~Hz})$ for ${ }^{13} \mathrm{C},{ }^{15} \mathrm{~N}$, and ${ }^{31} \mathrm{P}$ and small values $(<1 \mathrm{~Hz})$ for ${ }^{1} \mathrm{H}$ and homonuclear ${ }^{6,7} \mathrm{Li},{ }^{6,7} \mathrm{Li}$ coupling. The sensitivity of various new NMR techniques for small coupling constants is thus 

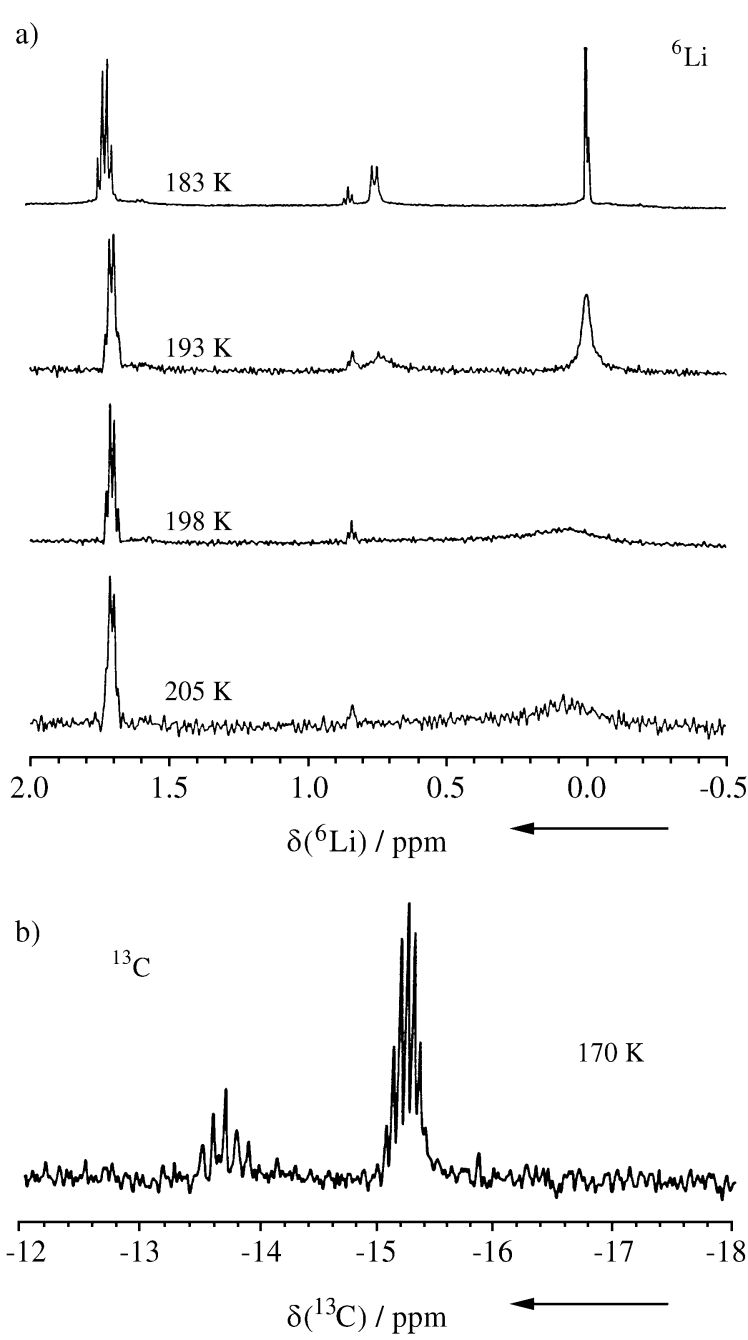

Figure 12. a) Temperature dependence of the ${ }^{6} \mathrm{Li}-\mathrm{NMR}$ spectrum of an equimolar mixture of $\mathrm{CH}_{3} \mathrm{Li} / \mathrm{CD}_{3} \mathrm{Li}$ and two moles of $\mathrm{LiBr}$ in [D8] THF; b) ${ }^{13} \mathrm{C}$-NMR signals observed for an equimolar mixture of $\mathrm{CH}_{3} \mathrm{Li} / \mathrm{LiBr}$ in [D8]THF at $170 \mathrm{~K}$.

of considerable interest if ${ }^{6,7} \mathrm{Li},{ }^{1} \mathrm{H}$ or ${ }^{6,7} \mathrm{Li},{ }^{6,7} \mathrm{Li}$ coupling is to be detected.

It is important to remember that information about the structure of the various aggregates of RLi systems which are formed in solution in the presence or absence of stabilizing diamines and other ligands comes primarily from spin-spin coupling or nuclear Overhauser effects which involve lithium and to a lesser extent from chemical shift data of the ligands. $\mathrm{X},{ }^{1} \mathrm{H}$ coupling $\left(\mathrm{X}={ }^{1} \mathrm{H},{ }^{13} \mathrm{C},{ }^{15} \mathrm{~N},{ }^{31} \mathrm{P}\right)$ within the ligands $\mathrm{R}$ does not yield information about aggregate size or structure and coupling between protons or $\mathrm{X}$ nuclei of different ligands $\mathrm{R}$ is normally not observed. Thus, in this context ${ }^{6,7} \mathrm{Li}, \mathrm{X}$ and homonuclear ${ }^{6,7} \mathrm{Li},{ }^{6,7} \mathrm{Li}$ couplings are of fundamental importance.

\section{Homonuclear experiments}

From the various homonuclear 2D NMR experiments which can be applied to detect and measure scalar spin-spin coupling, the COSY, COSY-DQF, TOCSY and INADEQUATE experiment ${ }^{60}$ were used in this context successfully for ${ }^{6} \mathrm{Li},{ }^{6} \mathrm{Li}$ spin systems. Experiments whith ${ }^{6} \mathrm{Li}$ generally profit from the smaller linewidth of ${ }^{6} \mathrm{Li}$ as compared to ${ }^{7} \mathrm{Li}$ signals, but the larger ${ }^{7} \mathrm{Li}$, ${ }^{7} \mathrm{Li}$ coupling (factor $2.64^{2} \sim 7$ due to the ratio $\left.\gamma\left({ }^{7} \mathrm{Li}\right) / \gamma\left({ }^{6} \mathrm{Li}\right)=2.64\right)$ is an attractive feature of ${ }^{7} \mathrm{Li},{ }^{7} \mathrm{Li}$ experiments, since small splitting might lead to an elimination of cross peaks in the 2D spectra if antiphase components result. The identification of homonuclear ${ }^{6,7} \mathrm{Li},{ }^{6,7} \mathrm{Li}$ coupling, which sofar has never been resolved in a normal 1D Li-NMR spectrum, is important in cases were several non-isochronous ${ }^{6,7} \mathrm{Li}$-NMR signals are observed.$^{61}$ Those belonging to the same cluster can then be recognized if homonuclear coupling exists, which requires short lithium distances typical for Li-C-Li arrangements. It is not clear if coupling between the two Li nuclei is transmitted directly or as a geminal interaction via the carbon.

From the 2D techniques cited above, the INADEQUATE $^{62}$ and the COSY-DQF ${ }^{63}$ experiment have the additional advantage of a built-in double quantum filter which eliminates any true singlet from the observed spectrum. For the detection of ${ }^{6} \mathrm{Li},{ }^{6} \mathrm{Li}$ coupling, the INADEQUATE experiment is most easily applied with appreciable time saving in its $1 \mathrm{D}$ version, ${ }^{64}$ recently performed also for ${ }^{7} \mathrm{Li}$ (Fig. 13). But it is also an attractive choice for other applications and was used to measure for the first time a homonuclear ${ }^{15} \mathrm{~N},{ }^{15} \mathrm{~N}$ coupling in a mixed aggregate of lithiated amides. As is well known from investigations by Collum et al. ${ }^{12}$ lithium diisopropylamide (LDA) forms dimers in $\mathrm{THF}^{65}$ and cyclic trimers and higher cyclic oligomers in hydrocarbon solvents ${ }^{66}$. For a 1:1 mixture of ${ }^{15} \mathrm{~N}$ and ${ }^{6} \mathrm{Li}$ labeled LDA and lithium di(3-pentyl)amide (LDPA) in THF we observed the expected four ${ }^{15} \mathrm{~N}$ signals - two of them nearly degenerate - stemming from the symmetric aggregates $\underline{\mathbf{1 4}}$ and $\underline{\mathbf{1 6}}$ and the mixed aggregate $\underline{\mathbf{1 5}}$ (Fig. 14). All signals

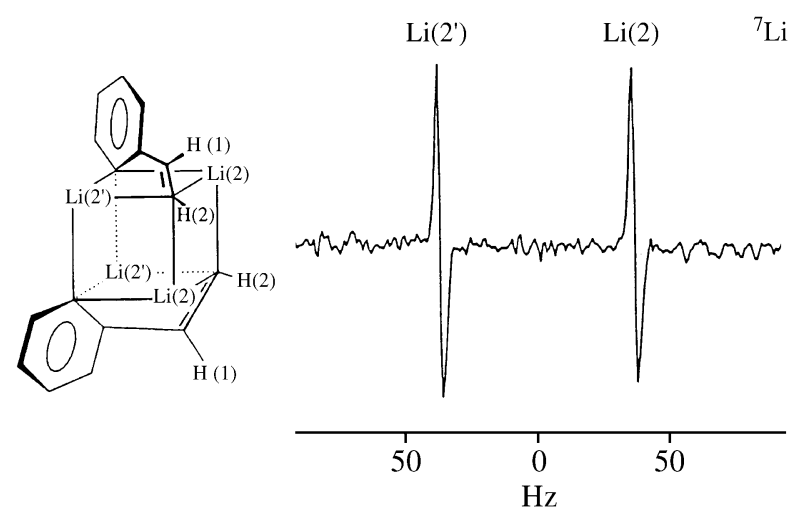

Figure 13. 155.6 MHz 1D INADEQUATE ${ }^{7} \mathrm{Li}$ spectrum of the dimer of (Z)-2-lithio-1-(o-lithiophenyl)ethene $0.3 \mathrm{M}$ in [D10]diethylether at RT; standard pulse sequence ${ }^{62-64}$ with $\Delta=1 / 2 J($ c. $500 \mathrm{~ms})$; the observed splitting amounts to $2.4 \mathrm{~Hz}$, but because of the $I={ }^{3} / 2$ spin of ${ }^{7} \mathrm{Li}$ it does not correspond in a simple way to the homonuclear ${ }^{7} \mathrm{Li},{ }^{7} \mathrm{Li}$ coupling. 


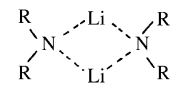

14

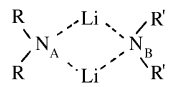

15

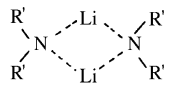

16

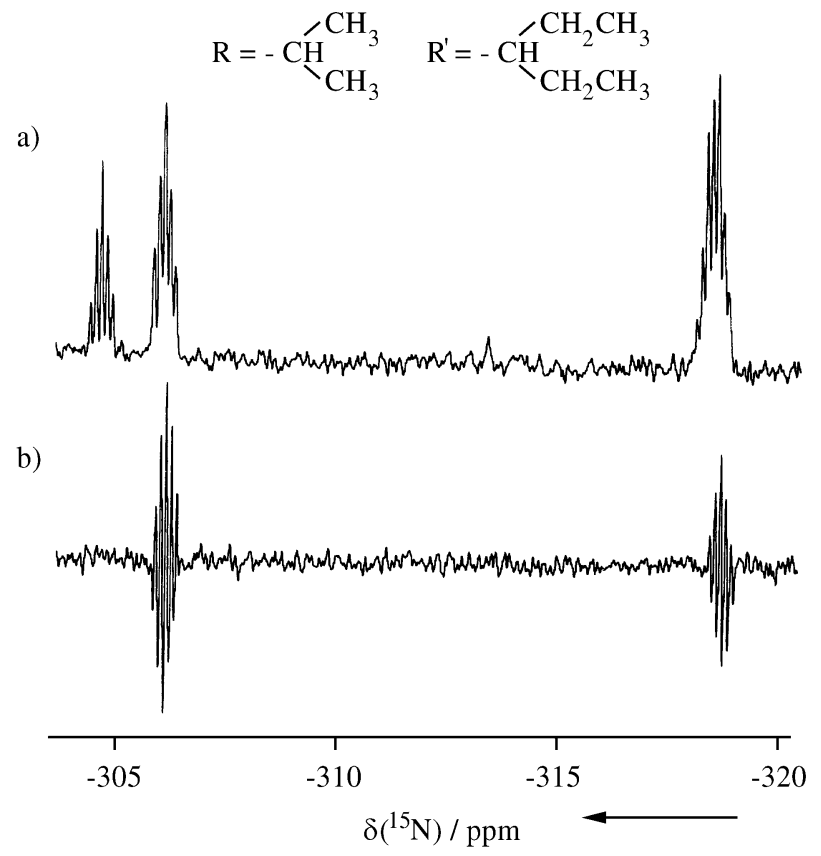

Figure 14. a) ${ }^{6} \mathrm{Li}$ coupled $40.5 \mathrm{MHz}{ }^{15} \mathrm{~N}-\mathrm{NMR}$ spectrum of an equimolar mixture of lithiumdiisopropylamide and lithium-di(3-pentyl)amide in [D8]THF at $200 \mathrm{~K}$; ref. ext. $\mathrm{CH}_{3}{ }^{15} \mathrm{NO}_{2}$; b) one-dimensional ${ }^{15} \mathrm{~N} ;{ }^{15} \mathrm{~N}$ INADEQUATE spectrum of the same mixture.

show quintuplet splittings due to coupling to two ${ }^{6} \mathrm{Li}$ with a coupling constant of $5.0 \mathrm{~Hz}$ (Fig. 14a).

The $1 \mathrm{D}{ }^{15} \mathrm{~N},{ }^{15} \mathrm{~N}$ INADEQUATE experiment (Fig. 14b), which selects coupled AX systems identifies the two signals belonging to ${ }^{15} \mathrm{~N}_{\mathrm{A}}$ and ${ }^{15} \mathrm{~N}_{\mathrm{B}}$ of the mixed aggregate which now show an additional antiphase splitting of $1.6 \mathrm{~Hz}$ due to the homonuclear geminal ${ }^{15} \mathrm{~N}_{\mathrm{A}},{ }^{15} \mathrm{~N}_{\mathrm{B}}$ coupling. A further observation of interest is the different intensity of the two ${ }^{15} \mathrm{~N}$ signals which results from different nuclear Overhauser effects in the two amide residues, where the larger number of protons in the LDPA part of the mixed cluster enhances the intensity of the ${ }^{15} \mathrm{~N}_{\mathrm{B}}$ signal. The ${ }^{15} \mathrm{~N}$ assignment which follows from this effect is in agreement with the assignment derived from substituent increments where a $\beta$-methyl group leads to a downfield shift ${ }^{67}$.

In changing the solvent to hexane the number of ${ }^{15} \mathrm{~N}$ signals increases which indicates also an increase of coexisting structures (Fig. 15a). The INADEQUATE experiment (Fig. 15b) selects two ${ }^{15} \mathrm{~N}$ AX systems which we assign to cyclic aggregates $(\mathrm{RLi})_{\mathrm{n}}$ with $\mathrm{n}=3$ or $4(\underline{\mathbf{1 7}}$, 18), because the homonuclear ${ }^{15} \mathrm{~N},{ }^{15} \mathrm{~N}$ coupling now drops to $1.0 \mathrm{~Hz}$. This is a strong indication of a structural

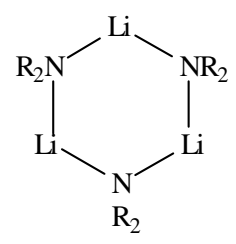

17

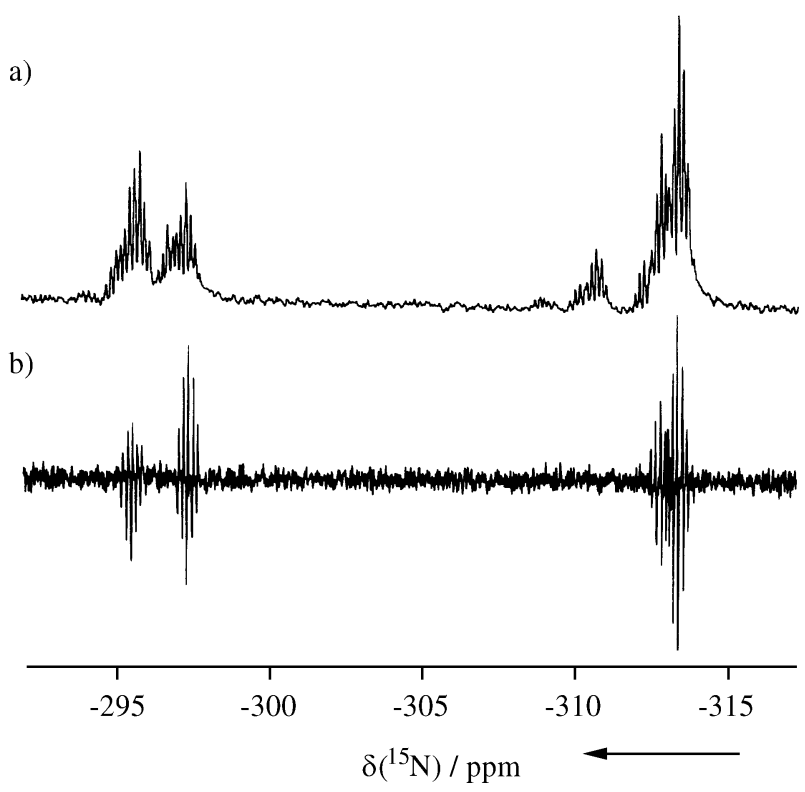

Figure 15. a) ${ }^{6} \mathrm{Li}$ coupled $40.5 \mathrm{MHz}{ }^{15} \mathrm{~N}-\mathrm{NMR}$ spectrum of an equimolar mixture of lithiumdiisopropylamide and lithium-di(3-pentyl)amide in $n$ hexane at $255 \mathrm{~K}$; ref. ext $\mathrm{CH}_{3}{ }^{15} \mathrm{NO}_{2}$; b) one-dimensional ${ }^{15} \mathrm{~N},{ }^{15} \mathrm{~N}$ INADEQUATE spectrum of the same mixture.

change to a cyclic trimer or a higher cyclic aggregate where only one coupling path is available between the two nitrogens.

\section{Analysis of ligand ${ }^{1} \mathrm{H}$ spectra}

For the analysis of ligand structures, ${ }^{1} \mathrm{H}$-NMR plays an important part in many cases and the possibility to start magnetization transfer selectively is an attractive feature of several 1D versions of well-known 2D NMR experiments. For example, the selective homonuclear ${ }^{1} \mathrm{H}$ TOCSY experiment ${ }^{60,68-70}$, improved by trim pulses $(\mathrm{TP})^{71}$ and a $z$-filter ${ }^{69}$ (pulse sequence (1)) can be employed to unravel the strongly coupled ${ }^{1} \mathrm{H}$ spectrum of cyclohexyllithium. As shown in Fig. 16, starting the magnetization transfer at the tertiary proton adjacent to the metal, which has a resonance well separated from the remaining signals by its low-field shift, axial and equatorial protons at subsequent ring positions are differentiated by the variable mixing time. 


$$
\begin{aligned}
& 90^{\circ}--\frac{\mathrm{t}_{1}}{2}--180^{\circ}--\frac{\mathrm{t}_{1}}{2}--\mathrm{TP}, \mathrm{MLEV} 17, \mathrm{TP}, \\
& 90^{\circ}(\mathrm{x}), \tau_{2}, 90^{\circ}(\phi), \text { FID }
\end{aligned}
$$

Another application of selective excitation is indicated if deuteriated isotopomers of certain solvents are not easily available and ${ }^{1} \mathrm{H}$ signals of interest might overlap with large solvent peaks. Selective excitation of the particular spin system then allows elimination of the solvent signals and the inspection of spectral regions which were before masked by the solvent lines. An example is shown in Fig. 17 with the application of a 1D COSY experiment ${ }^{70}$ to the ${ }^{1} \mathrm{H}$ spectrum of isopropyllithium, a compound that forms tetramers and hexamers in hydrocarbon solvents. ${ }^{72,73}$ At around $200 \mathrm{~K}$ in pentane the tetramer/hexamer ratio is ca. 10:1. Here we start with a selective $90^{\circ}$ pulse, thereby

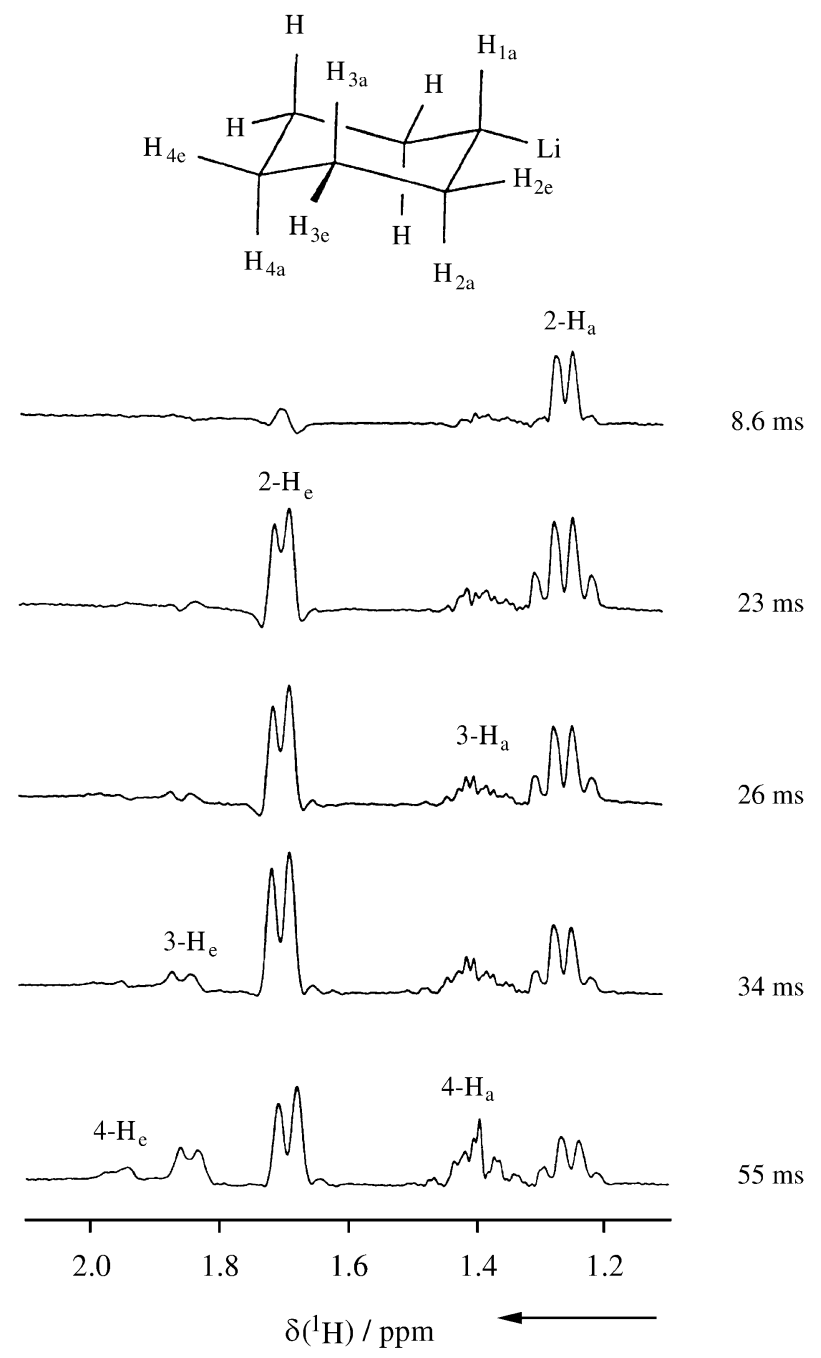

Figure 16. One-dimensional ${ }^{1} \mathrm{H}$-TOCSY spectra of cyclohexyllithium with variation of the mixing time provided by the MLEV method (pulse sequence (1)); $1-\mathrm{H}_{2}$ at $-0.9 \mathrm{ppm}$ not shown. defining the origin of the magnetization transfer which follows (pulse sequence (2)), The detection of the methyl resonances of both aggregates, which are hidden under the huge solvent lines, allows the chemical shifts of the methyl protons and the vicinal ${ }^{1} \mathrm{H},{ }^{1} \mathrm{H}$ coupling constants to be measured. An advantage is the antiphase character of both doublets, which facilitates the extraction of the NMR parameters by discriminating artefacts.

$$
90^{\circ}(\mathrm{sel})----\Delta_{1}----90^{\circ}, \mathrm{FID}
$$

\section{Heteronuclear shift correlations}

Heteronuclear shift correlations have been used quite frequently with success to correlate ${ }^{1} \mathrm{H},{ }^{13} \mathrm{C},{ }^{15} \mathrm{~N}$, and ${ }^{31} \mathrm{P}$ signals with the relevant ${ }^{6} \mathrm{Li}$ resonances of the aggregates of interest and in many cases the appropriate experiments with ${ }^{2} \mathrm{H}$ as a spin- 1 nucleus have paved the way ${ }^{74-79}$. Over the years, these experimental techniques have been considerably improved and especially the so-called inverse tech-

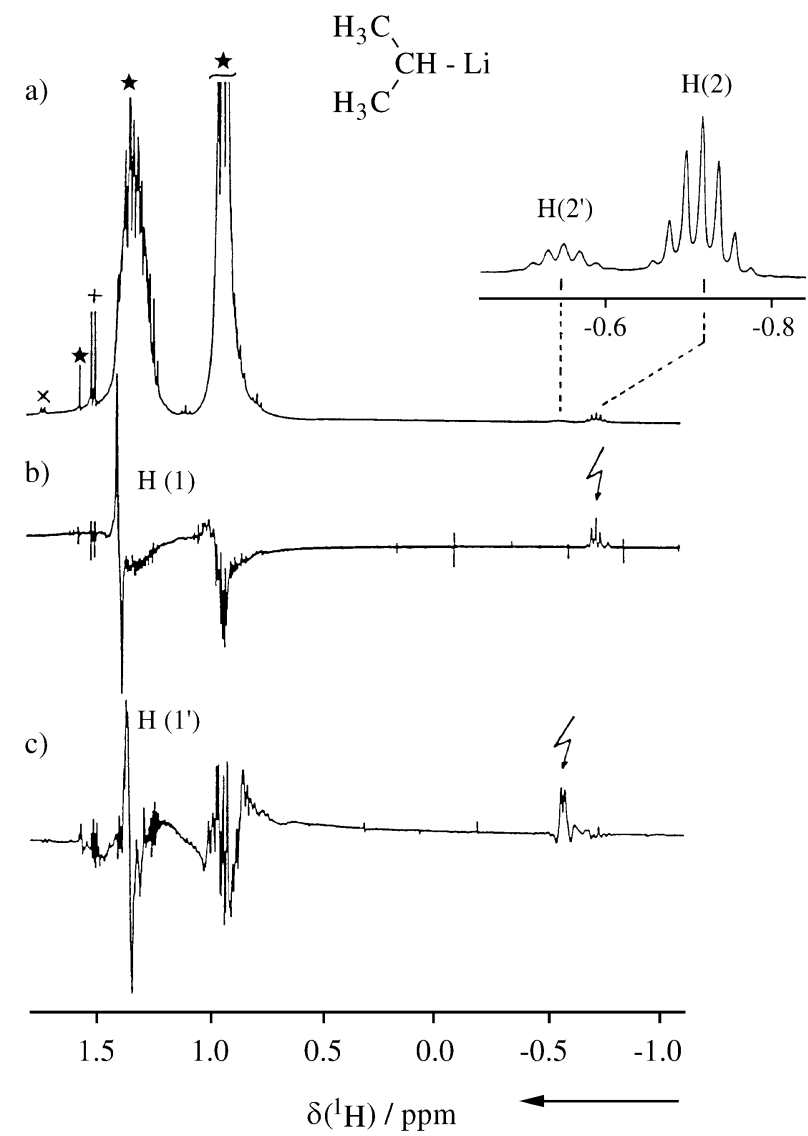

Figure 17. a) One-dimensional ${ }^{1} \mathrm{H},{ }^{1} \mathrm{H}$-COSY spectrum (pulse sequence (2)) of isopropyllithium $1.4 \mathrm{M}$ in $n$-pentane at $200 \mathrm{~K}$; (*) solvent signals, (+) educt signal, (x) signal from propene b) selective excitation at the resonance of $\mathrm{H}(1)$ of the tetramer by magnetization transfer from $\mathrm{H}(2)$; c) selective excitation at the resonance of $\mathrm{H}\left(1^{\prime}\right)$ of the hexamer by magnetization transfer from $\mathrm{H}\left(2^{\prime}\right)$. 
niques based on multiple quantum coherences ${ }^{80}$ (the HMQC experiment, pulse sequence (3)), where the experimental success relies on the suppression of uncoupled $I$ magnetization, have profited from hardware developments, the application of additional pulses ${ }^{81}$ like the BIRD sequence $^{82}$, and more recently from the introduction of linear field gradients ${ }^{60,83}$.

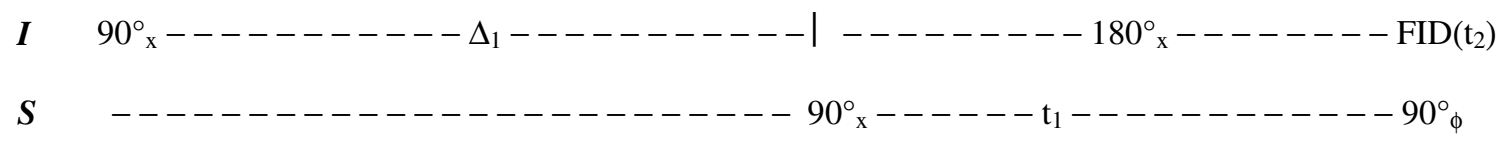

The inverse ${ }^{13} \mathrm{C},{ }^{6} \mathrm{Li}$ experiment with ${ }^{6} \mathrm{Li}$ detection (pulse sequence (3), $I={ }^{6} \mathrm{Li}, S={ }^{13} \mathrm{C}$ ), which was used for the first successful realization of a two-dimensional ${ }^{13} \mathrm{C},{ }^{6} \mathrm{Li}$ shift correlation, ${ }^{76}$ not only yields correlation information, but also allows ${ }^{13} \mathrm{C},{ }^{6} \mathrm{Li}$ coupling constants to be determined since usually the $S$ nucleus is not decoupled during $I$ signal acquisition (Fig. 18a). This experiment can also be performed most effectively and time saving by the corresponding 1D version (pulse sequence (4)), as demonstrated in Fig. $18 \mathrm{c}$.

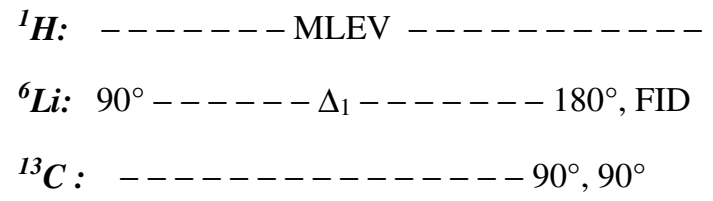

A recent addition to the list of $\mathrm{X},{ }^{6} \mathrm{Li}$ correlations is the ${ }^{29} \mathrm{Si},{ }^{6} \mathrm{Li}$ experiment based on sizable scalar ${ }^{29} \mathrm{Si},{ }^{6} \mathrm{Li}$ coupling $^{84}$. An example is shown in Fig. 19 with the result for the dimer of $(E)$-1-lithio-2-(o-lithiophenyl)-1-trimethylsilylethene (Fig. 19).

\section{Heteronuclear Overhauser spectroscopy}

Finally, turning to ${ }^{1} \mathrm{H},{ }^{6} \mathrm{Li}$ nuclear Overhauser spectroscopy, the $2 \mathrm{D}{ }^{1} \mathrm{H},{ }^{6} \mathrm{Li}$ HOESY experiment ${ }^{85}$ is one of the important tools in structure elucidation of organolithium compounds $^{57}$. Recent developments in this field have led to the proposal of the inverse experiment with ${ }^{1} \mathrm{H}$ detection which has the advantage of higher spectral dispersion in the ${ }^{1} \mathrm{H}$ domain. The idea was originally put forward already in 1990 by Bauer and Schleyer ${ }^{86 a}$, but only the introduction

b)

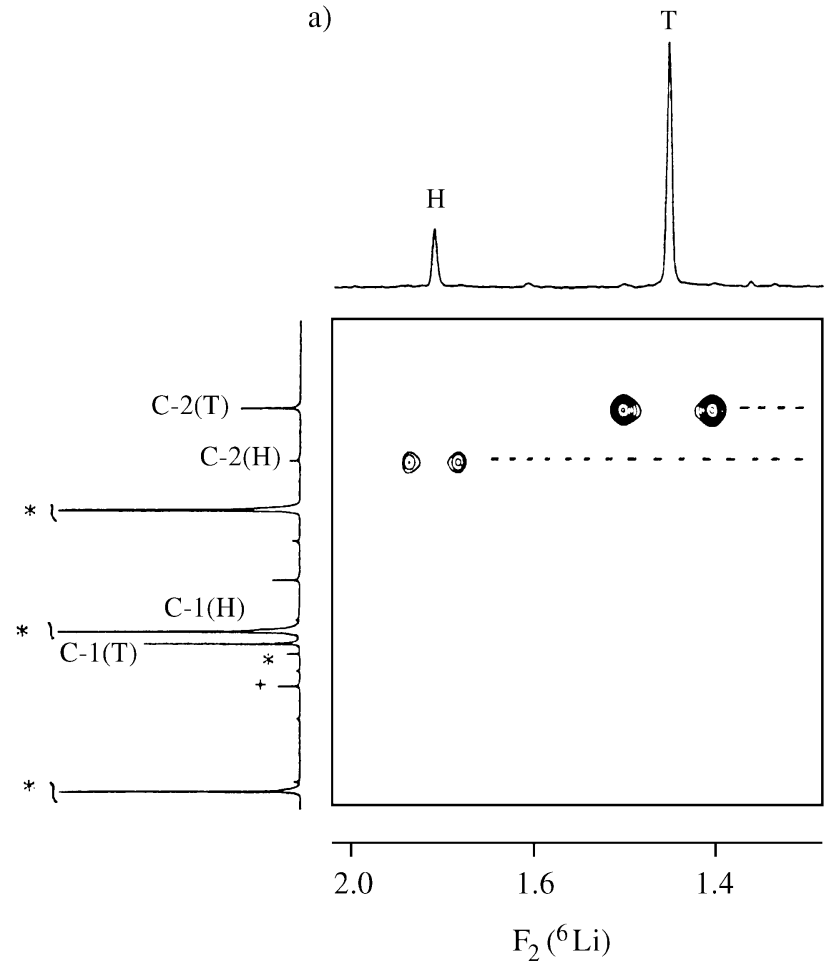

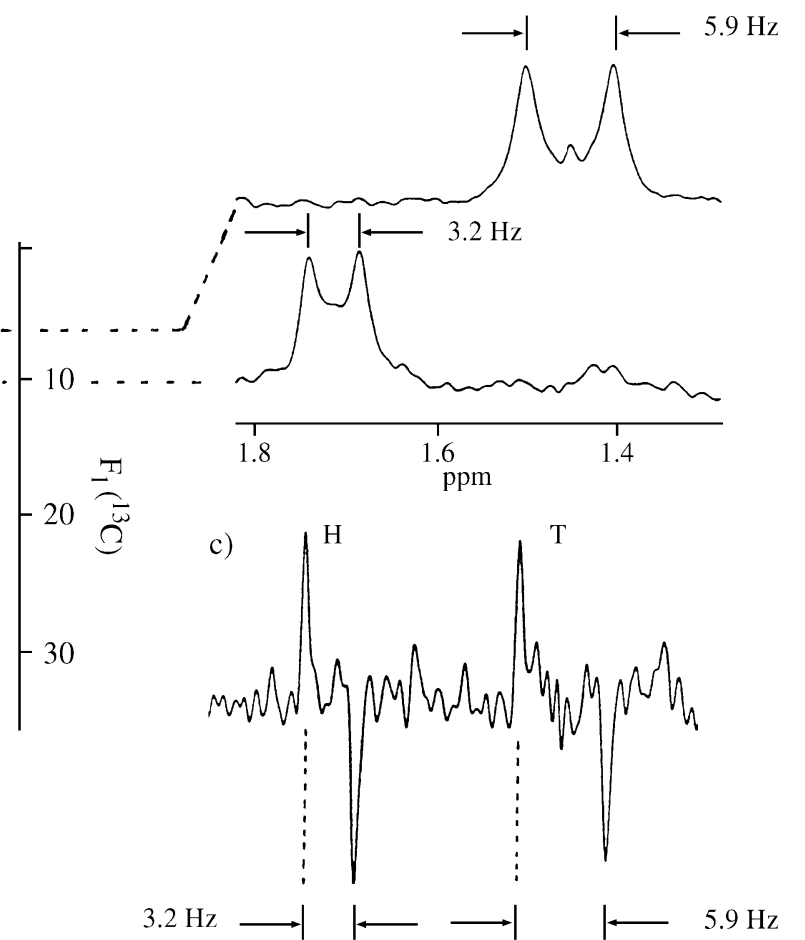

Figure 18. a) Two-dimensional inverse ${ }^{6} \mathrm{Li},{ }^{13} \mathrm{C}$ shift correlation (pulse sequence (3)) for the oligomers of isopropyllithium $1.4 \mathrm{M}$ in $n$-pentane at $220 \mathrm{~K}$; exp. time $7 \mathrm{~h}$; b) $F_{2}$ traces of the crosspeaks with ${ }^{6} \mathrm{Li},{ }^{13} \mathrm{C}$ coupling constants, typical for hexameric $(3.2 \mathrm{~Hz})$ and tetrameric $(5.9 \mathrm{~Hz})$ aggregates; c) result of a one-dimensional experiment (pulse sequence (4)) showing the ${ }^{13} \mathrm{C}$ satellites in the ${ }^{6} \mathrm{Li}$ spectrum; exp. time $40 \mathrm{~min}(\mathrm{H}=$ hexamer, $\mathrm{T}=$ tetramer). 


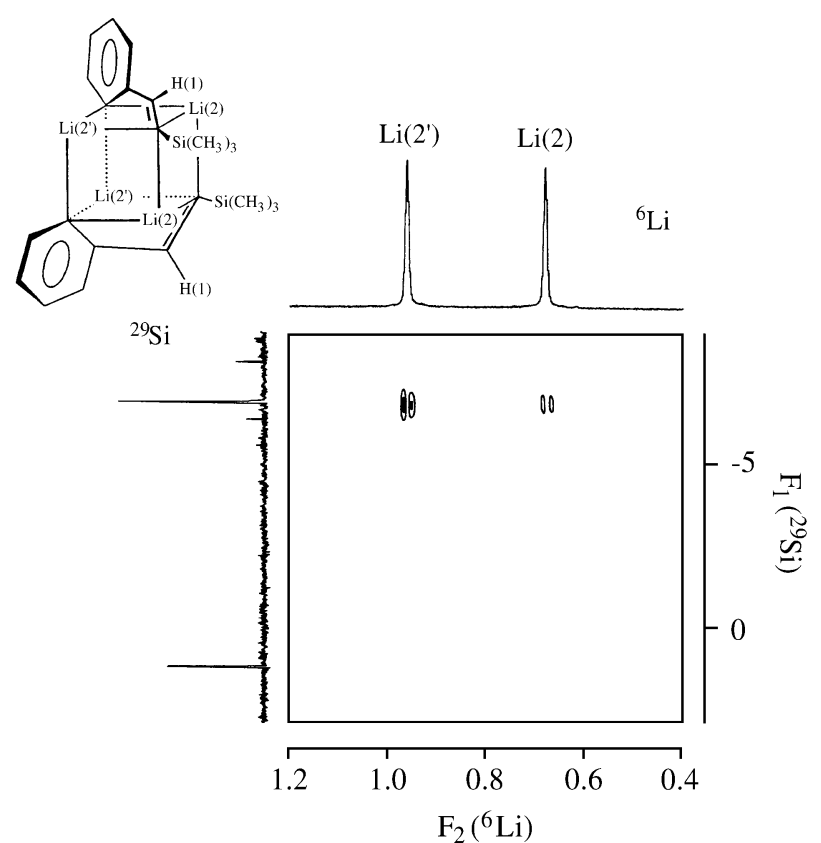

Figure 19. Two-dimensional ${ }^{6} \mathrm{Li}$ detected $58.88 / 79 \mathrm{MHz}{ }^{6} \mathrm{Li},{ }^{29} \mathrm{Si}\left\{{ }^{1} \mathrm{H}\right\}$ HMQC experiment for (pulse sequence (3)) for the dimer of $(E)$-1-lithio2-(o-lithiophenyl)-1-trimethylsilylethene (0.3M in [D8]THF at $135 \mathrm{~K})$; the delay $\Delta_{1}$ was set to $37.5 \mathrm{~ms}$, the signal splitting is $0.9 \mathrm{~Hz}$; exp. time = $8 \mathrm{~h} 48 \mathrm{~min}$

of linear $B_{\mathrm{o}}$ field gradient techniques paved the way for a practical solution of the experimental difficulty to eliminate the dominating proton magnetization which is not due to a heteronuclear ${ }^{6} \mathrm{Li} \rightarrow{ }^{1} \mathrm{H} \mathrm{NOE}^{86 \mathrm{~b}}$. It was found that the experiment is best performed with the ${ }^{7} \mathrm{Li},{ }^{1} \mathrm{H}$ spin pair, apparently due to the stronger dipolar interactions and the faster relaxation rate of ${ }^{7} \mathrm{Li}$ as compared to ${ }^{6} \mathrm{Li}$.

In an attempt to transfer these ideas to the one-dimensional version of the NOE measurement, we based our experiments on results reported by Keeler et al. ${ }^{87}$ for gradient enhanced ${ }^{1} \mathrm{H},{ }^{1} \mathrm{H}$ nuclear Overhauser (GOESY) spectroscopy and introduced two frequency channels along the lines of the $2 \mathrm{D}{ }^{1} \mathrm{H},{ }^{6} \mathrm{Li}$ HOESY experiment. This leads to a pulse sequence shown in Fig. 20, which takes advantage of a later version of the GOESY experiment ${ }^{88}$. Here, the first part up to the gradient pulse $\mathrm{G}_{4}$ serves for the selection of the desired ${ }^{7} \mathrm{Li}$ magnetization, $I\left({ }^{7} \mathrm{Li}\right)_{\text {sel }}$, of a particular lithium resonance, ${ }^{7} \mathrm{Li}_{\mathrm{k}}$, which is to be transferred to the protons. Therefore, the conditions $\mathrm{G}_{1}=\mathrm{G}_{2}$ and $\mathrm{G}_{3}=\mathrm{G}_{4}$ refocus $I\left({ }^{7} \mathrm{Li}\right)_{\text {sel }}$ because the two selective $180^{\circ}$ pulses change the sign of the coherences. The $90^{\circ}{ }^{1} \mathrm{H}$ pulse produces transverse proton magnetization which is destroyed by the gradient pulse $\mathrm{G}_{5}$, leaving for detection only the Overhauser enhancement which builds up during the mixing time through transfer from the selected nucleus ${ }^{7} \mathrm{Li}_{\mathrm{k}}$.

Experimental results for the well characterized dimer of (Z)-2-lithio-1-(o-lithiophenyl)ethen ${ }^{89}$ are shown in Fig. 21. In spectrum b) we see strong NOE's between $\mathrm{Li}(2)$ and both

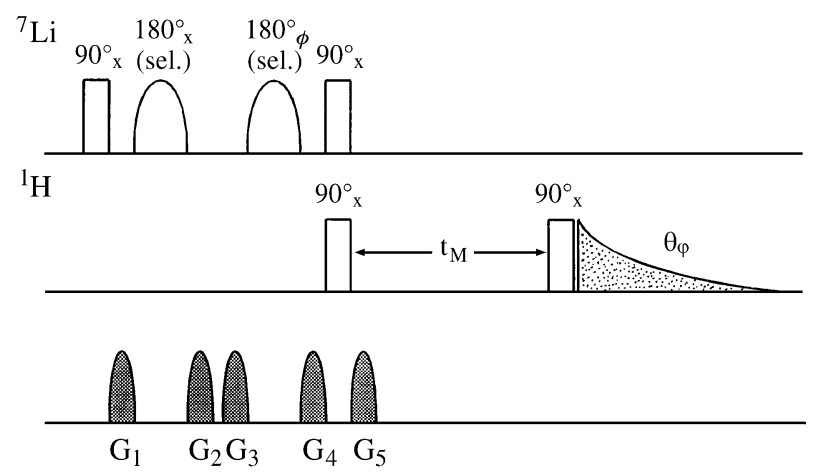

Figure 20. Pulse sequence for gradient enhanced ${ }^{1} \mathrm{H}$-detected ${ }^{7} \mathrm{Li},{ }^{1} \mathrm{H}$ one-dimensional nuclear Overhauser spectroscopy (cf. text); additional phase cycle $\Phi=0^{\circ}, 90^{\circ}, 180^{\circ}, 270^{\circ} ; \varphi=0^{\circ}, 180^{\circ}, 0^{\circ}, 180^{\circ}$.

olefinic protons, in spectrum c) between $\mathrm{Li}\left(2^{\prime}\right)$ and $\mathrm{H}(3)$ at the aromatic ring. Weaker responses are coming in spectrum b) for $\mathrm{H}(3)$ and in spectrum c) for $\mathrm{H}(1)$ and $\mathrm{H}(2)$. In contrast, the $2 \mathrm{D}{ }^{1} \mathrm{H},{ }^{6} \mathrm{Li}$ HOESY spectrum (Fig. 21d) shows only the relationships $\mathrm{Li}(2) / \mathrm{H}(2)$ and $\mathrm{Li}\left(2^{\prime}\right) / \mathrm{H}(3)$ which are also the strongest in the $1 \mathrm{D}$ experiment.

Noteworthy is the enormous time advantage of the 1D sequence: these spectra were recorded within $35 \mathrm{~min}$, while for the HOESY experiment $13 \mathrm{~h}$ had to be invested!

\section{The Benzyllithium Story}

\section{Ach wie gut daß niemand weiß, daß ich Rumpelstilzchen hei $\beta$}

Despite the power of modern NMR experiments, even in the case of simple organolithium systems all attempts to determine their solution structure may fail due to a variety of reasons, among which are low solubility and fast exchange dynamics. One of these small molecules, which preserved until recently the secret of its detailed structure in solution, is benzyllithium. Even today, all facets of this structural problem may not have been uncovered.

Early X-ray crystallographic studies for solids consisting of benzyllithium and donors like triethylamine ${ }^{90}$ or diethylether $^{91}$ as ligands revealed chain structures with Li-C $\mathrm{C}_{\alpha}$ distances of 217 and $221 \mathrm{pm}$, respectively, and different orientations of the $\mathrm{Li}$ cation with respect to the benzyl residue. With respect to the solution structure, the results of calculations by various semi-empirical and abinitio methods ${ }^{92}$ are of interest, which suggested that in principle three alternative structures (19 - 21) may be discussed for solvated benzyllithium and its $\alpha$-substituted derivatives ( $\mathrm{L}=$ solvent or complexing ligand). Following MNDO results for the heat of formation ${ }^{93}$, the energy difference between the $\eta^{1}$ and $\eta^{3}$ structure is rather small ( $4 \mathrm{kcal} /$ mole, see next page).

Indeed, experimental evidence for a $\eta^{1} \rightleftharpoons \eta^{3}$ equilibrium was presented in the case of $\alpha$-(dimethylamino)benzyllithium in THF solution ${ }^{94}$. 

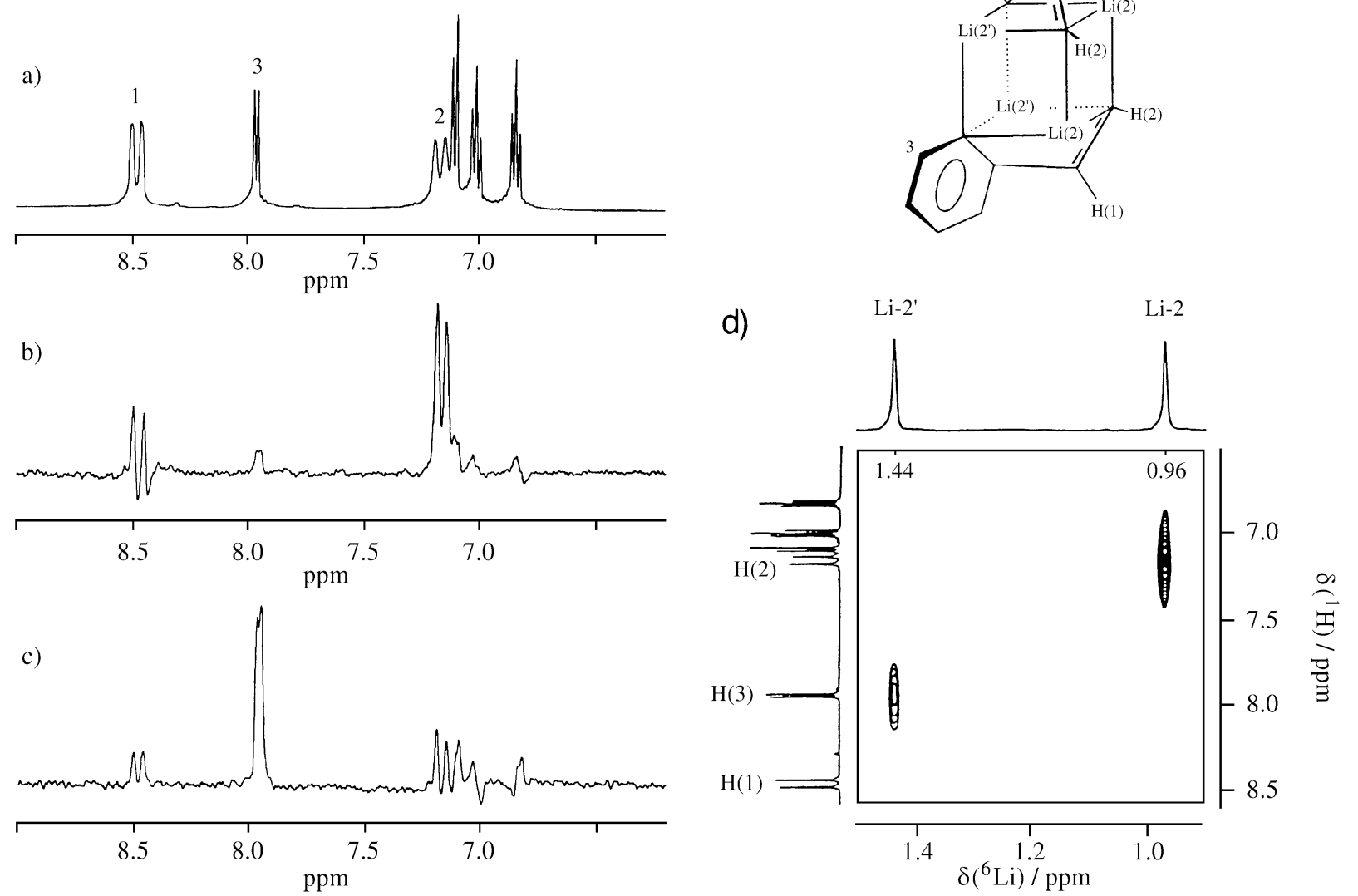

Figure 21. a) - c) One dimensional gradient enhanced ${ }^{1} \mathrm{H}$-detected ${ }^{7} \mathrm{Li},{ }_{1}^{1} \mathrm{H}$ nuclear Overhauser spectra for the dimer of $(Z)$-2-lithio-1-(o-lithiophenyl)ethene $0.3 \mathrm{M}$ in [D10]diethylether at RT (cf. text); d) two-dimensional ${ }^{1} \mathrm{H},{ }^{6} \mathrm{Li}$ HOESY spectrum for the same sample.

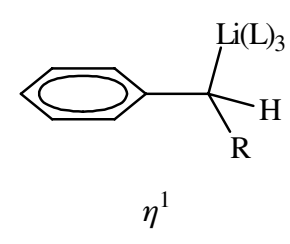

$\underline{19}$

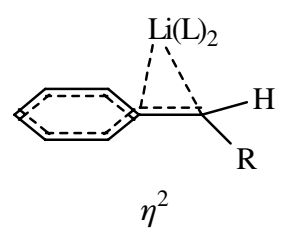

$\underline{20}$

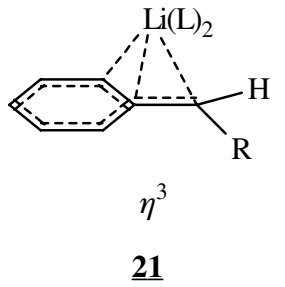

For solids, Boche et al. focused again attention to this structural problem by reporting the results of an X-ray investigation for the [benzyllithium,THF,TMEDA] com$\operatorname{plex}^{93}$. These workers found a monomeric $\eta^{1}$ structure with pyramidal $\mathrm{C}_{\alpha}$ and a $\mathrm{Li}-\mathrm{C}_{\alpha}$ distance of $221 \mathrm{pm}$. Among the various $\alpha$-substituted benzyl systems which have been studied by X-ray diffraction ${ }^{95}$, the trimethylsilyl substituted

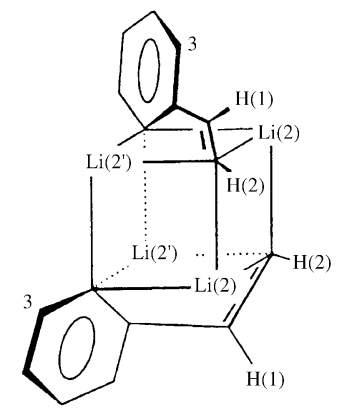


<smiles>[AlH]Cc1c2cccc1COCCOCCOCCOCCOC2</smiles>

22<smiles>[AlH]C1S[C@@H]2COCCOCCOCCOCCOCc3cccc2c31</smiles>

23

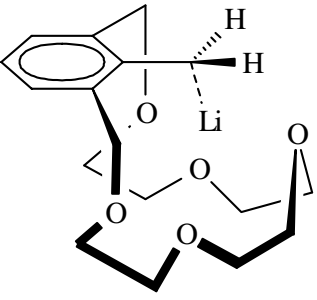

24 distance of 213 pm was found in the crystal ${ }^{96}$ and according to ${ }^{1} \mathrm{H},{ }^{6} \mathrm{Li}$ and ${ }^{13} \mathrm{C}$, ${ }^{6} \mathrm{Li}$ HOESY measurements ${ }^{97}$, the same or a closely related structure prevails in solution.

The earliest solution studies ${ }^{98}$ had already indicated that benzyllithium is monomeric, but in the NMR spectrum of ${ }^{6} \mathrm{Li}$ labeled material no ${ }^{13} \mathrm{C},{ }^{6} \mathrm{Li}$ coupling constant was found. ${ }^{99}$ This is also true for $\alpha$-substituted derivatives ${ }^{100}$, with the single exception of a phenylsubstituted cyclopropyl system ${ }^{101}$. Consequently, for solute samples one could expect solvent separated ion pairs or fast equilibria between contact ion pairs or dynamic processes between both structural alternatives. The existence of rapid dynamic processes was also indicated by the low configurational stability of $\alpha$-substituted derivatives ${ }^{102}$.

Findings reported recently carry our understanding of these structural aspects a step further. By chaining up the lithium cation to $\mathrm{C}_{\alpha}$ via a crown ether 'necklace', Hoffmann and Boche et al. ${ }^{103}$ were able to observe for the first time a scalar ${ }^{13} \mathrm{C}_{\alpha},{ }^{6,7} \mathrm{Li}$ coupling constant in compounds $\underline{\mathbf{2 2}}$ and $\underline{\mathbf{2 3}}$ in THF at $203 \mathrm{~K}\left(\underline{\mathbf{2 2}}: J\left({ }^{13} \mathrm{C}_{\alpha},{ }^{7} \mathrm{Li}\right)=7.0 \mathrm{~Hz}, \underline{\mathbf{2 3}}: J\left({ }^{13} \mathrm{C}_{\alpha},{ }^{6} \mathrm{Li}\right)\right.$ $=3.1 \mathrm{~Hz}$ which corresponds to $\left.J\left({ }^{13} \mathrm{C}_{\alpha},{ }^{7} \mathrm{Li}\right)=9.0 \mathrm{~Hz}\right) .{ }^{1} \mathrm{H},{ }^{6} \mathrm{Li}$ HOESY experiments suggest an arrangement such as that shown in $\underline{\mathbf{2 4}}$ for these monomeric systems.

At the same time, using a similar strategy, Fraenkel and Martin ${ }^{104}$ found ${ }^{13} \mathrm{C}_{\alpha},{ }^{6} \mathrm{Li}$ couplings of 2.8 and $3.4 \mathrm{~Hz}$ in THF at $250 \mathrm{~K}$ for the two compounds $\underline{\mathbf{2 5 a}}$ and $\underline{\mathbf{2 5} \mathbf{b}}$ and we observed ${ }^{13} \mathrm{C},{ }^{6} \mathrm{Li}$ couplings $(2.7 \mathrm{~Hz})$ for the lithium cation trapped in the organic ligand of the Schlenk dimer $\underline{\mathbf{2 6}}$ where the second lithium exists as a solvent separated ion ${ }^{105}$. Even more interesting, Fraenkel and Martin ${ }^{104}$ were able to meas- ure a ${ }^{13} \mathrm{C}_{\alpha},{ }^{6} \mathrm{Li}$ coupling of $3.8 \mathrm{~Hz}$ for the parent compound itself in the presence of TMEDA, using ${ }^{13} \mathrm{C}$ and ${ }^{6} \mathrm{Li}$ labeling, low concentration ( $0.005 \mathrm{M}$ in THF), and low temperature $(180 \mathrm{~K})$. Thus, finally the conversation of the $\mathrm{C}_{\alpha}$ and ${ }^{6,7} \mathrm{Li}$ spin was tapped, but the low value of the coupling constants is unexpected in view of the findings that monomers usually show ${ }^{13} \mathrm{C}$, ${ }^{6} \mathrm{Li}$ coupling close to $17 \mathrm{~Hz}^{99}$. Fraenkel assumes that this suggests the existence of a continuum of covalency between 'classical' monomers with large coupling and solvent separated ion pairs with no coupling at all. But, as mentioned above, the benzyllithium system is probably still good for a number of surprises.

\section{Compounds with $\pi$ - and $\sigma$-Bound Lithium}

some like it hot

The strong shielding and deshielding effects exerted by cyclic $\pi$-systems on surrounding protons has long fascinated annulene chemists who coined the terms diatropic and paratropic to describe the diamagnetic and paramagnetic shielding properties of $(4 n+2)$ and $(4 n) \pi$-systems, respectively. ${ }^{106}$ In particular the oxidation or reduction of neutral hydrocarbons to the corresponding dications or dianions, respectively, has generated interesting systems where the difference in the number of $\pi$-electrons results in spectacular shielding and deshielding effects in proton NMR spectra ${ }^{107}$. An example from our laboratory is the generation of methano[10]annulene dianion (으) from methano[10]annulene (27) by reduction with lithium metal. $^{108}$

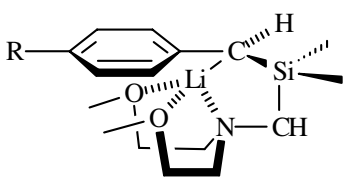

25a $\mathrm{R}=\mathrm{H}$ 25b $\mathrm{R}=\mathrm{C}\left(\mathrm{CH}_{3}\right)_{3}$

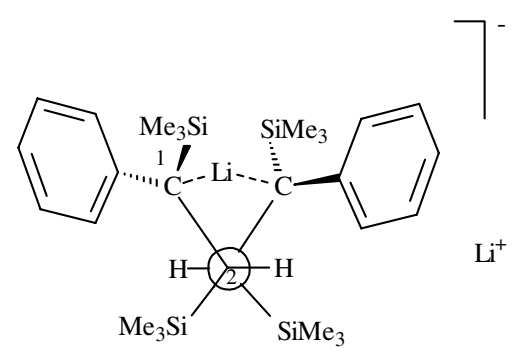

26 
<smiles>Cc1cccc2ccccc12</smiles>

$\delta(\mathrm{CH}) \quad 6.95,7.27 \mathrm{ppm}$

27

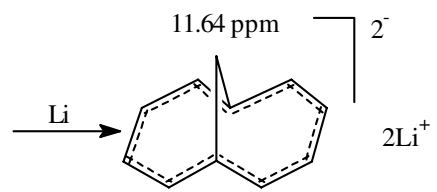

$3.09,1.27 \mathrm{ppm}$

28
The transformation $\underline{\mathbf{2 7}} \rightarrow \underline{\mathbf{2 8}}$ was achieved after earlier unsuccessful attempts by using ultrasonic radiation or by simply attaching the sealed NMR tube with the parent hydrocarbon and lithium sand in THF to the rod of a vibrational mixer. This technique was also successful in the case of biphenylene, were we had found ${ }^{109}$ that the dianion 29, formed initially via reduction by potassium in THF, reacts with protic solvents to yield benzocyclo-octatetraene (31) via the Woodward-Hoffmann allowed ring opening reaction of the primarily formed $4 \mathrm{a}, 8 \mathrm{~b}$-dihydrobiphenylene $(\underline{\mathbf{3 0}})$. In the absence of proton donors, $\underline{\mathbf{2 9}}$ has a half-life of $1.7 \mathrm{~h}$ and opens the four-membered ring to yield $o, o^{\prime}-$ dilithiodiphenyl $(\underline{\mathbf{3 2}})^{110}$, a compound with a lithium double bridge ${ }^{111}$.

\section{The reduction of benzoannelated Biphenylenes}

In an attempt to study this reaction in the case of benzoannulated biphenylenes, we treated benzo[b]biphenylene ( $\underline{\mathbf{3 3}})$ with lithium sand in diethylether. Instead of the dianion we found immediate formation of 2-o-lithiophenyl-3-lithionaphthalene ( $\underline{\mathbf{3 4}}$ ), which yields a purple solution and is characterized by two $\mathrm{ABCD}$ systems and two singlets in the ${ }^{1} \mathrm{H}-\mathrm{NMR}$ spectrum. Two carbon resonances at 174.2 and $176.0 \mathrm{ppm}$ and a ${ }^{6} \mathrm{Li}$ singlet at $2.30 \mathrm{ppm}$ (rel. to ext. $0.1 \mathrm{M} \mathrm{LiBr}$ in THF) complete the information which is significant for the structure.

In contrast, the oxidation of the hydrocarbon $\underline{\mathbf{3 3}}$ with the 'Olah mixture' $\mathrm{SbF}_{5} / \mathrm{SO}_{2} \mathrm{ClF}$ at $-30{ }^{\circ} \mathrm{C}$ yielded the $14 \pi$ electron system $\mathbf{3 5}$ which is, at that temperature, perfectly stable. Its Q-value ${ }^{112}$ of 1.43 as determined from the bond orders derived on the basis of the vicinal $\mathrm{H}, \mathrm{H}$ coupling constants ${ }^{3} J(6,7)$ and ${ }^{3} J(7,8)$ via analysis of the ${ }^{1} \mathrm{H}$-NMR spectrum, is typical for a benzoannelated diatropic system, in the present case the $10 \pi$ electron system of biphenylene dication.
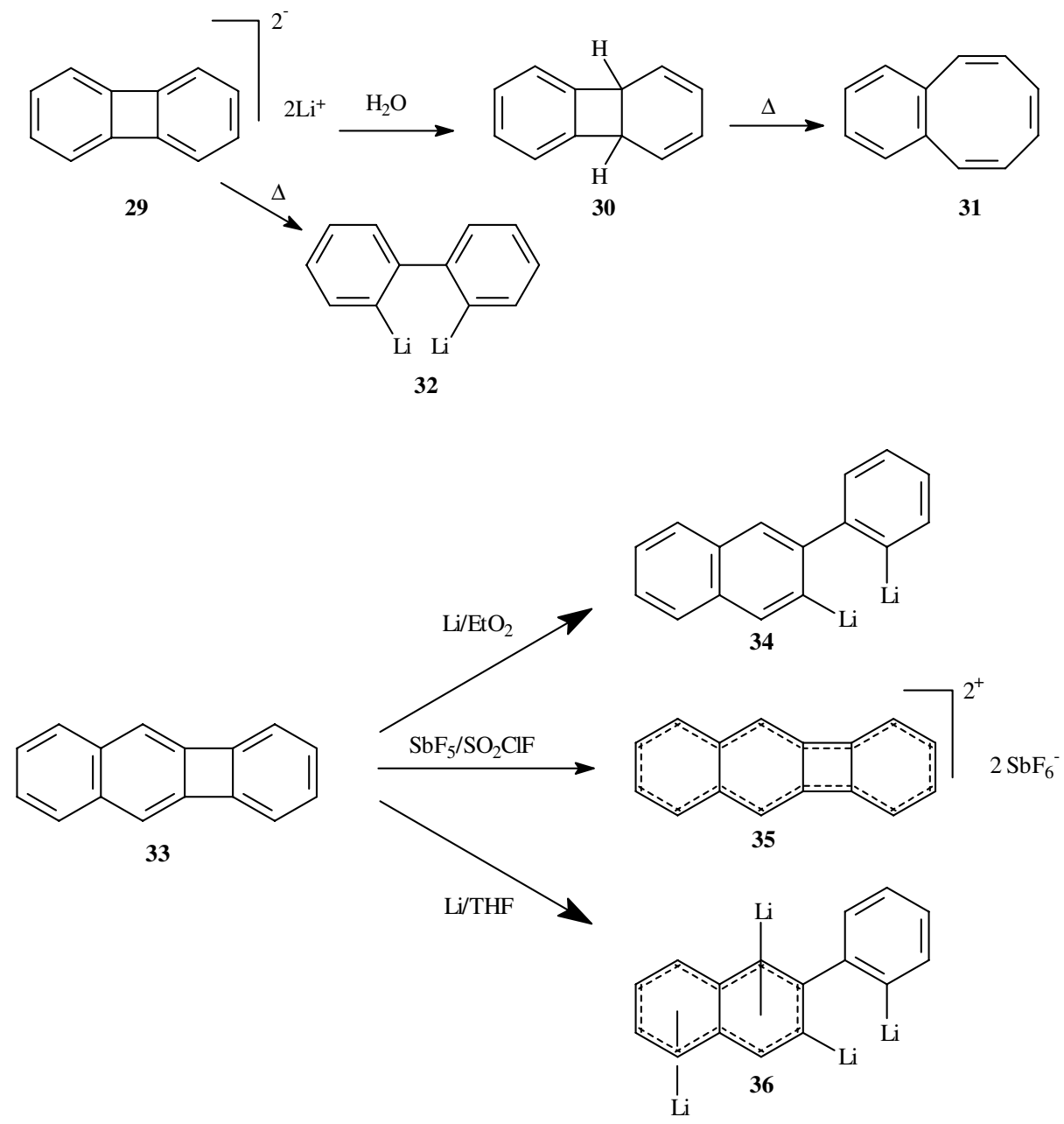
<smiles></smiles>

37<smiles>CCc1ccc2cc3c(cc2c1)-c1cc2ccccc2cc1-3</smiles>

39<smiles>CCCCCCC</smiles><smiles>c1ccc2c(c1)-c1cc3cc4ccccc4cc3cc1-2</smiles><smiles>c1ccc2c(c1)-c1cc3cc4ccccc4cc3cc1-2</smiles>

40<smiles>c1ccc2c(c1)-c1ccc3ccccc3c1-2</smiles>

41

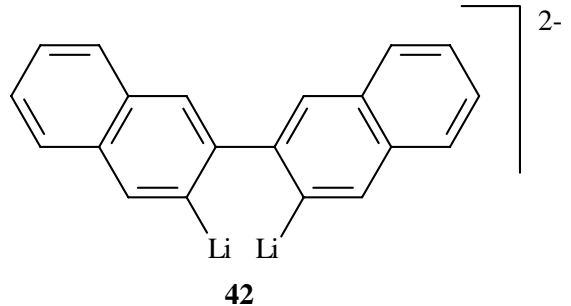

42

Completely different NMR spectra were observed when the reduction of $\underline{\mathbf{3 3}}$ was carried out in THF. In particular the ${ }^{1} \mathrm{H}$ - spectrum showed spectacular high-field shifts for some of the protons, which resonate at 2.25 and $2.60 \mathrm{ppm}$. Similar spectacular high-field shifts for 'aromatic' protons were found before in the case of dilithionaphthalenediide ${ }^{113}$. Most conclusive evidence for the structure of the new product came from the deuteron NMR spectrum of the deuterolysis product, which showed four signals, two in the allylic, one in the olefinic, and one in the aromatic region. All spectroscopic data, including the ${ }^{13} \mathrm{C}$ and ${ }^{6} \mathrm{Li}$ spectra, where in accord with the tetralithiated structure 36 which has $\pi$ - and $\sigma$-bound lithium as a unique feature $^{114}$. Additional proof for the proposed structure came from an experiment where $\underline{\mathbf{3 4}}$ was prepared in diethylether and further reduction was carried out after replacing this solvent by THF.

The interesting structural properties of $\underline{\mathbf{3 6}}$ with $\pi$ - and $\sigma$-bound lithium initiated related studies for dibenzo $[b, h]$ biphenylene $(\underline{\mathbf{3 7}})$ and naphtho $[b]$ biphenylene $(\underline{\mathbf{3 8}})^{115}$. In both cases reduction with lithium sand in diethylether yielded the dianions, $\underline{\mathbf{3 9}}$ and $\underline{\mathbf{4 0}}$, respectively, which could be fully characterized by their NMR spectra.<smiles>CCc1ccccc1-c1cc2cc3ccccc3cc2cc1I</smiles>

Surprisingly, however, both are paratropic systems with high-field shifted ${ }^{1} \mathrm{H}$ resonances $(2.81,4.49$, and $4.98 \mathrm{ppm}$ for $\underline{39}$, and 2.40, 3.43 and $3.96 \mathrm{ppm}$ for $\mathbf{4 0}$ ), despite the total number of $22 \pi$-electrons. The Q-values are 0.963 for $\underline{\mathbf{3 9}}$ and 0.982 for $\underline{40}$ and point in the same direction. The NMR data of $\underline{\mathbf{3 9}}$ closely resemble those of dilithionaphthalenediide which suggests a mesomeric structure $\underline{\mathbf{3 9 a}} \leftrightarrow \underline{\mathbf{3 9 b}}$, while $\underline{40}$ resembles a phenylene-annelated anthracene dianion. In contrast to the dianions of the linear annelated systems, the dianion of the angular annelated benzo[a]biphenylene (1) is perfectly stable. If $\underline{\mathbf{3 7}}$ and $\underline{\mathbf{3 8}}$ are reduced in THF, again four-membered ring opening and a second reduction to the new tetralithio compounds $\underline{\mathbf{4 2}}$ and $\underline{43}$ is observed.

\section{Conclusion}

The topics discussed show how a variety of high-resolution NMR techniques can be used in structural research in the field of organolithium compounds. Isotope shifts as well as homo- and heteronuclear shift correlations and nuclear Overhauser spectroscopy provide detailed informations about the aggregation behavior of lithiated carbon compounds which are important synthetic aids. In particu- 
lar techniques which utilize the nuclides ${ }^{6} \mathrm{Li}$ and ${ }^{7} \mathrm{Li}$ yield valuable insights into the course of lithiation reactions, aggregate formation and dynamics.

\section{Acknowledgements}

As far as our own efforts in the field of organolithium chemistry and its NMR spectroscopy are concerned, I am deeply obliged to my coworkers for their enthusiastic collaboration. In particular I thank Werner Andres, Rainer Benken, Klaus Bergander, Bernd Böhler, Oswald Eppers, Thomas Fox, Maria-Eugenia Günther, Heike Hausmann, Runxi He, Dietmar Hüls, Martin Kreutz, Hans-Egbert Mons, Detlef Moskau, and Cirsten Zaeske for their fine contributions. Many ideas and stimulations came from my colleague, Prof. Dr. Adalbert Maercker, Siegen, and his coworkers, which is gratefully acknowledged. Thanks for financial support is due to the Deutsche Forschungsgemeinschaft, the Fonds der Chemischen Industrie, and the Chemetall Company, Frankfurt.

\section{References}

1. Harris, R.K. In NMR and the Peridic Table; Harris, R.K.; Mann, B.E., eds.; Academic Press; London, p. $1,1978$.

2.Akitt, J.W. In Multinuclear NMR; Mason, J., ed.; Plenum Press; New York, p. 189, 1987.

3. Laszlo, P. In The Multinuclear Approach to NMR Spectroscopy; Lambert, J.B.; Riddell, F.G., eds.; D. Reidel; Dordrecht, Holland, p. 261, 1983.

4. Laszlo, P. Sodium-23 Nuclear Magnetic Resonance, Angew. Chem. 1978, 90, 271; Angew. Chem. Int. Ed. Engl. 1978, 17, 254.

5. Lutz, O. In The Multinuclear Approach to NMR Spectroscopy; Lambert, J.B.; Riddell, F.G., eds.; D. Reidel, Dordrecht, Holland, p. 297, 1983.

6. Drakenberg, T. Ann. Rep. NMR Spectrosc. 1986, 17, 231.

7.Laszlo, P.; Sodium-23 NMR, In Encyclopedia of NMR;. Grant, D.; Harris, R.K., eds.; Wiley; Chichester, v. 7, p. 4451, 1996.

8. Günther, H.; Moskau, D.; Schmalz, D. Angew. Chem. 1987, 99, 1242; Angew. Chem. Int. Ed. Engl. 1987, 26, 1212.

9. Thomas, R.D. In Isotopes in the Physical and Biomedical Sciences; Buncel, E.; Jones, J.R., eds.; Elsevier, Amsterdam, p. 367, 1991.

10. Jackman, L.M. and Bortiatynski, J. In Advances in Carbanion Chemistry; Snieckus, V., ed.; Jai Press, Greenwich, Connecticut, p. 45, 1992.

11. Bauer, W.; Schleyer, P.v.R. In Advances in Carbanion Chemistry; Snieckus, V., ed.; Jai Press, Greenwich, Connecticut, 1992, p. 89.
12. Collum, D.B. Acc. Chem. Res. 1993, 26, 227.

13. a) Günther, H., Lithium NMR, Encyclopedia of NMR; Grant, D.M.; Harris, R.K., eds.; Wiley, 1996, v. 5, p. 2807; b) H. Günther, High-resolution ${ }^{6,7}$ Li-NMR of Organolithium Compounds, In Advanced Applications of NMR to Organometallic Chemistry, Gielen, M.; Willem, R.; Wrackmeyer, B., eds., Wiley \& Sons, Chichester 1996.

14. Forsén, S.; Drakenberg, T.; Wennerstroem, H.; NMR Studies of Ion Binding in Biological Systems; Q. Rev. Biophys. 1987, 19, 83.

15. Johansson, C.; Drakenberg, T. Metal Ion NMR Studies of Ion Binding; Ann. Rep. NMR Spectrosc. 1990, $22,1$.

16. de Freitas, M. Alkali Metal Nuclear Magnetic Resonance; Methods Enzymol. 1993, 227, 78.

17. Miller, S.K.; Elgavish, G.A. Biol. Magn. Reson. 1992, $11,159$.

18. Allis, J.L. Ann. Rep. NMR Spectrosc. 1993, 26, 211.

19. Forsén, S.; Johansson, C.; Linse, S. Methods Enzymol. 1993, 227, 107.

20. Forsén, S.; Calcium Binding Proteins, In Encyclopedia of NMR; Grant, D. and Harris, R.K., Eds.; Wiley, Chichester, v. 2, p. 1092, 1996.

21. Kohler, S.J.; Kolodny, N.H. Sodium Magnetic Resonance Imaging and Chemical Shift Imaging, Progr. NMR Spectrosc. 1992, 24, 411.

22. Joseph, P.M. Sodium-23 Magnetic Resonance Imaging, In Encyclopedia of NMR; Grant, D.; Harris, R.K., eds.; Wiley, Chichester, v. 7, p. 4445, 1996.

23. Edwards, P.P.; Ellaboudy, A.; Holton, D.M.; Pype, N.C. Ann. Rep. NMR Spectrosc. 1988, 20, 315.

24. Tycko, R. Solid State Nucl. Magn. Reson. 1994, 3, 303.

25. Maniwa, Y.; Mizoguchi, K.; Kume, K. Kotai Butsuri 1994, 29, 839 (Japanese).

26. Tycko, R. J. Phys. Chem. Solids 1993, 54, 1712.

27. Lauginie, P.; Messaoudi, A.; Conard, J. Synth. Meth. 1993, 56, 3002.

28. Grandjean, J.; Laszlo, P. ACS Symp. Ser. 1989, 415, 396.

29. Chemical Society Specialists Reports: NMR Spectroscopy $1980 \mathrm{ff}$.

30. Chemical Society Specialists Reports: Spectroscopic Properties of Organometallic Compounds $1980 \mathrm{ff}$.

31. Bauer, W.; Magn. Reson. Chem. 1991, 29, 494.

32. Bauer, W.; Lochmann, L. J. Am. Chem. Soc. 1992, $114,7482$.

33. Benn, R.; Lehmkuhl, K.; Mehler, K.; Rufinska, A. Angew. Chem. Int. Ed. Engl. 1984, 23, 534.

34. Benn, R.; Rufinska, A. Angew. Chem. Int. Ed. Engl. 1986, 25, 861 . 
35. Lehmkuhl, K.; Mehler, K.; Benn, R.; Rufinska, A.; Kriger, C. Chem. Ber. 1986, 119, 1054.

36 Lin, Y.-Y.; Ge, N.-H.; Hwang, L.-P. J. Magn. Reson. Ser. B, 1994, 103, 189.

37. For an early review see Batiz-Hernandez, H.; Bernheim, R.A. Progr. NMR Spectrosc. 1967, 3, 63.

38. Hansen, P.E. Ann. Rep. NMR Spectrosc. 1983, 15, 106

39. Forsyth, D.A. In Isotopes in Organic Chemistry; Buncel, E.; Lee, C.C., eds.; Elsevier, Amsterdam, v. 6, p. 1, 1984.

40. Hansen, P.E. Progr. NMR Spectrosc. 1988, 15, 105.

41. Berger, S. In NMR - Basic Principles and Progress; Diehl, P.; Fluck, E.; Günther, H.; Kosfeld, R.; Seelig, J., eds.; Springer, Heidelberg, v. 22, p. 1, 1990.

42. For the latest reviews on theory and experiment of NMR isotope shifts see Jameson, C. In Encyclopedia of NMR; Grant, D.; Harris, R.K., eds.; Wiley, Chichester, 1996, v. 4, p. 2638; de Dios, A.C.; Jameson, C. Ann. Rep. NMR Spectrosc. 1994, 29, 1

43. Wesener, J.R.; Moskau, D.; Günther, H.; J. Am. Chem. Soc. 1985, 107, 7307.

44. Wesener, J.R.; Günther, H. Tetrahedron Lett. 1982, 2845; Ernst, L.; Eltamany, S.; Hopf, H. J. Am. Chem. Soc. 1982, 104, 299; Ernst, L.; Hopf, H.; Wullbrand, D. J. Am. Chem. Soc. 1983, 105, 4469; Schaefer, T.; Peeling, J.; Wildman, T.A. Can. J. Chem. 1983, 61, 2777; Forsyth, D.A.; Botkin, J.H.; Osterman, V.M.; J. Am. Chem. Soc. 1984, 106, 7663; Forsyth, D.A.; Yang, J.-R. J. Am. Chem. Soc. 1986, 108, 2154; Siehl, H.; Walter, H. J. Chem. Soc. Chem. Commun. 1985, 76; Schaefer, T.; Peeling, J.; Sebastian, R. Can. J. Chem. 1986, 65, 534; Berger, S.; Diehl, B.W.K.; Künzer, H.; Chem. Ber. 1987, 120, 1059.

45. Majerski, Z.; Zuanic, M.; Metelko, B. J. Am. Chem. Soc. 1985, 107, 1721; Aydin, R.; Frankmölle, W.; Schmalz, D.; Günther, H. Magn. Reson. Chem. 1988, 26, 408.

46. Aydin, R.; Günther, H. J. Am. Chem. Soc. 1981, 103, 1301

47. Günther, H.; Jikeli, G. Chem. Ber. 1973, 106, 1863.

48. Reuben, J.; J. Am. Chem. Soc. 1983, 105, 3711.

49. Christofides, J.C.; Davies, D.B. J. Am. Chem. Soc. 1983, 105, 5099.

50. Berger, S.; Künzer, H. Angew. Chem. 1983, 95, 321; Angew. Chem. Int. Ed. Engl. 1983, 22, 321

51. As a shift phenomenon, the measurement of NMR isotope effects profits from high $\mathrm{B}_{0}$ fields and the use of the lately introduced 750 or even $800 \mathrm{MHz}$ instruments may well lead to the detection of hitherto unobserved isotope shifts.

52. Eppers, O. and Günther, H. Helv. Chim. Acta 1990 , 73, 2071.
53. Seitz, L.M.; Brown, T.L. J. Am. Chem. Soc. 1966, 88, 2174.

54. Attempts to measure ${ }^{2} \mathrm{H}$-induced isotope shifts for ${ }^{7} \mathrm{Li}$ sofar failed because of the larger linewidth as compared to ${ }^{6} \mathrm{Li}$, which furthermore increases at low temperature in the slow exchange limit due to increasing quadrupole relaxation.

55. Schmidbaur, H.; Schier, A.; Schubert, U. Chem. Ber. 1983, 116, 1938.

56. Eppers, O.; diploma thesis, University of Siegen, 1988; Günther, H. In Recent Developments in Molecular Spectroscopy; World Scientific, Singapore, p. 457, 1989.

57. Bauer, W. In: Lithium Chemistry - A Theoretical and Experimental Overview; Saspe, A.M.; Schleyer, P.v.R., eds.; Wiley, Chichester, p. 125, 1995.

58. Novak, D.P.; Brown, D.L. J. Am. Chem. Soc. 1972, 94, 3793.

59. Waak, R.; Doran, M.A.; Baker, E.B. Chem. Commun. 1967, 1291.

60. For an outstanding review on experimental aspects of one- and two-dimensional NMR experiments see: a) Hull, W.E. In Two-Dimensional NMR Spectroscopy Applications for Chemists and Biochemists; Croasmun, W.R.; Carlson, R.M.K., Eds.; VCH Publishers, Weinheim, p. 67, 1994; b) Berger, S.; Braun, S.; Kalinowski, H.-O. 150 and More Basic NMR Experiments, $2^{\text {nd }}$ ed., Wiley-VCH, Weinheim, 1998.

61. Günther, H.; Moskau, D.; Dujardin, R. and Maercker, A. Tetrahedron Lett 1986, 27, 2251; Bauer, W.; Feigel, M.; Müller, G. and Schleyer, P.v.R. J. Am. Chem. Soc. 1988, 110, 6033; Gallagher, D.J.; Kerrick, S.T.; Beak, P. J. Am. Chem. Soc. 1992, 114, 5872.

62. Bax, A.; Freeman, R.; Kempsell, P.S. J. Am. Chem. Soc. 1980, 102, 4849; Bax, A.; Freeman, R.; Frenkiel, T.A. J. Am. Chem. Soc. 1981, 103, 2102.

63. Bax, A.; Freeman, R. J. Magn. Reson. 1981, 44, 542. 64. Eppers, O.; Fox, T. and Günther, H. Helv. Chim. Acta 1992, 75, 883.

65. Galiano-Roth, A.S.; Michaelides, E.M.; Collum, D.B. J. Am. Chem. Soc. 1988, 110, 2658; Galiano-Roth, A.S.; Collum, D.B. J. Am. Chem. Soc. 1989, 111, 6772; Romesberg, F.E.; Collum, D.B. J. Am. Chem. Soc. 1992, 114, 2112; Romesberg, F.E.; Gilchrist, J.H.; Harrison, A.T.; Fuller, D.J.; Collum, D.B. J. Am. Chem. Soc. 1991, 113, 5751.

66. Kim, Y.-J.; Bernstein, M.P.; Galiano-Roth, A.S.; Romersberg, F.E.; Williard, P.G.; Fuller, D.J.; Harrison, A.T.; Collum, D.B. J. Org. Chem. 1991, 56, 4435.

67. Levy, G.C.; Lichter, R.L. Nitrogen-15 Nuclear Magnetic Resonance Spectroscopy, Wiley; New York, p. $37 \mathrm{ff}, 1979$. 
68. Davis, D.G.; Bax, A. J. Am. Chem. Soc. 1985, 107, 7197.

69. Subramanian, S.; Bax, A. J. Magn. Reson. 1987, 71, 325.

70. Kessler, H.; Anders, U.; Gemmecker, G.; Steuernagel, S. J. Magn. Reson. 1989, 85, 1.

71. Bax, A.; Davis, D.G. J. Magn. Reson. 1985, 65, 355.

72. Lewis, H.L.; Brown, T.L. J. Am. Chem. Soc. 1970, 92, 4664.

73. Thomas, R.D.; Jensen, R.M.; Young, T.C. Organometallics 1987, 6, 565.

74. Bauer W. and Griesinger, C. J. Am. Chem. Soc. 1993, $115,10871\left({ }^{1} \mathrm{H}\right)$.

75. Mons, H.-E.; Günther, H.; Maercker, A. Chem. Ber. 1993, 126, $2747\left({ }^{1} \mathrm{H}\right)$.

76. Moskau, D.; Brauers, F.; Günther, H.; Maercker, A. J. Am. Chem. Soc. 1987, 109, $5532\left({ }^{13} \mathrm{C}\right)$.

77. Gais, H.-J.; Vollhardt, J.; Günther, H.; Moskau, D.; Lindner, H.J.; Braun, S. J. Am. Chem. Soc. 1988, 110, $978\left({ }^{13} \mathrm{C}\right)$.

78. Gilchrist, J.H.; Harrison, A.T.; Fuller, D.J.; Collum, B.D. Magn. Reson. Chem. 1992, 30, $855\left({ }^{15} \mathrm{~N}\right)$.

79. Romesberg, F.E.; Bernstein, M.P.; Gilchrist, J.H.; Harrison, A.T.; Fuller, D.J.; Collum, D.B. J. Am. Chem. Soc. 1993, 115, $3475\left({ }^{31} \mathrm{P}\right)$.

80. Müller, L. J. Am. Chem. Soc. 1979, 101, 4481; Bax, A.; Griffey, R.H.; Hawkins, B.L. J. Magn. Reson. 1983, 55, 301

81. Brühwiler, D.; Wagner, G. J. Magn. Reson. 1986, 69, 546; Bax, A.; Subramanian, S. J. Magn. Reson. 1986, $69,565$.

82. Garbow, J.R.; Weitekamp, D.P.; Pines, A. Chem. Phys. Lett. 1982, 93, 504.

83. Hurd, R.E.; John, B.K. J. Magn. Reson. 1991, 91, 468; Vuister, G.W.; Boelens, R.; Kaptein, R.; Hurd, R.E.; John, B.K.; van Zijl, P.C.M. J. Am. Chem. Soc. 1991, 113, 9688; Tyburn, J.-M.; Brereton, I.M.; Doddrell, D.M. J. Magn. Reson. 1992, 97, 305.

84. Böhler, B; Günther, H. Tetrahedron Lett. 1996, 37, 8723.

85. Bauer, W.; Müller, G.; Pi, R.; Schleyer, P.v.R. Angew. Chem. 1986, 98, 1130; Angew. Chem. Chem. Int. Ed. Engl. 1986, 25, 1103.

86. a) Bauer, W.; Schleyer, P.v.R.; Poster A.3 at the $10^{\text {th }}$ European Experimental NMR Conference (EENC), Veldhoven, May 28 - June 1, 1990; b) Bauer, W. Magn. Reson. Chem. 1996, 34, 532.

87. Stonehouse, J.; Adell, P.; Keeler, J.; Shaka, A.J. J. Am. Chem. Soc. 1994, 116, 6037.

88. Stott, K.; Stonehouse, J.; Hwang, T.L.; Keeler, J.; Shaka, A.J. J. Am. Chem. Soc. 1995, 117, 4199.
89. Günther, H.; Eppers, O.; Hausmann, H.; Hüls, D.; Mons, H.-E.; Klein, K.-D. and Maercker, A. Helv. Chim. Acta 1995, 78, 1913.

90. Patterma, S.P.; Karle, T.L.; Stucky, G.D. J. Am. Chem. Soc. 1970, 92, 1130.

91. Beno, M.A.; Hope, H.; Olmstead, M.M.; Power, P.P. Organometallics 1985, 4, 2117.

92. Lipkowitz, K.B.; Uhegbu, C.; Naylor, A.M.; Vance, R. J. Comput. Chem. 1985, 6, 662; Sygula, A.; Rabideau, P.W. J. Org. Chem. 1987, 52, 3521; Sygula, A.; Rabideau, P.W. J. Am. Chem. Soc. 1992, 114, 821; Bühl, M.; v. Eikema Hommes, N.J.R.; Schleyer, P.v.R.; Fleischer, K.; Kutzelnigg, W. J. Am. Chem. Soc. 1991, 113, 2459.

93. Zarges, W.; Marsch, M.; Harms, K.; Boche, G. Chem. Ber. 1989, 122, 2303.

94. Ahlbrecht, H.; Harbach, J.; Hauck, T.; Kalinowski, H.-O. Chem. Ber. 1992, 125, 1753.

95. For a review of the relevant literature see Ref. 96.

96.Zarges, W.; Marsch, M.; Koch, W.; Frenking, G.; Boche, G. Chem. Ber. 1991, 124, 543.

97. Berger, S.; Müller, F. Chem. Ber. 1995, 128, 799.

98. West, R.; Waack, R. J. Am. Chem. Soc. 1967, 89, 4395.

99. Seebach, D.; Hässig, R. and Gabriel, J. Helv. Chim. Acta 1983, 66, 308.

100. see for example Schade, P.; Schäfer, T.; Müllen, K.; Bender, D.; Knoll, K.; Bronstert, K.; Chem. Ber. 1991, $124,2833$.

101. Hoell, D.; Lex, J.; Müllen, K. J. Am. Chem. Soc. 1986, 108, 5983.

102. Hoffmann, R.W.; Rühl, T.; Chemla, F.; Zahneisen, T. Liebigs Ann. Chem. 1992, 719; Hoffmann, R.W.; Rühl, T.; Harbach, J. Liebigs Ann. Chem. 1992, 725.

103. Ruhland, T.; Hoffmann, R.W.; Schade, S.; Boche, G. Chem. Ber. 1995, 128, 551.

104. Fraenkel, G.; Martin, K.V. J. Am. Chem. Soc. 1995, 117, 10336.

105. Böhler, B.; Hüls, D.; Günther, H. Tetrahedron Lett. 1996, 37, 8719.

106. Sondheimer, F.; Acc. Chem. Res. 1972, 5, 81.

107. Reviews: Müllen, K. Angew. Chem. 1987, 99, 192 Angew. Chem. Int. Ed. Engl. 1987, 26, 204; Müllen, K.; Chem. Rev. 1984, 84, 603.

108. Schmalz, D.; Günther, H. Angew. Chem. 1988, 100, 1754; Angew. Chem. Int. Ed. Engl. 1988, 27, 1692.

109. Günther, M.-E.; Aydin, R.; Buchmeier, W.; Engelen, B.; Günther, H. Chem. Ber. 1984, 117, 1069. 
110. Benken, R.; Finneiser, K.; v. Puttkamer, H.; Günther, H.; Eliasson, B.; Edlund, U. Helv. Chim. Acta. 1986, 69, 955.

111. Schubert, U.; Neugebauer, W.; Schleyer, P.v.R. J. Chem. Soc. Chem. Commun. 1982, 1184.

112. Cremer, D.; Günther, H.; Liebigs Ann. Chem. 1972, 763 , 87; Günther, H.; Vicinal ${ }^{1} \mathrm{H},{ }^{1} \mathrm{H}$ Coupling Constants in Cyclic $\pi$-Systems, Encyclopedia of NMR; Grant, D.M.; Harris, R.K., eds.; Wiley, v. 8, p. 4923, 1996.
113. Benken, R.; Günther, H. Helv. Chim. Acta. 1988, 71, 694.

114. Benken, R.; Andres, W.; Günther, H. Angew. Chem. 1988, 100, 1212 Angew. Chem. Int. Ed. Engl. 1988, 27, 1182 .

115 a) Andres, W. Ph.D. Thesis, University of Siegen 1991; b) Hausmann, H.; PhD. thesis, University of Siegen 1992; c) Günther, H.; Andres, W.; Hausmann, H.; unpublished. 